\title{
A steel-concrete composite beam element for structural damage identification
}

\author{
Faraz Sadeghi ${ }^{1}$, Jianchun $\mathrm{Li}^{1}$, Xinqun $\mathrm{Zhu}^{1}$ \\ ${ }^{1}$ Centre for Built Infrastructure Research (CBIR), School of Civil and Environmental Engineering, University of \\ Technology Sydney (UTS), Sydney, NSW 2007, Australia
}

Corresponding author: Faraz.Sadeghi@student.uts.edu.au; Jianchun.Li@uts.edu.au

\begin{abstract}
The composite action between the layers of steel and concrete is governed by the shear connection. Because of the complicated interconnection behaviour of these composite layers, it is difficult to detect damage in the composite structures, especially the interfacial integrity of the two layers. In this paper, a novel method has been developed for structural damage identification of composite structures based on a steel-concrete composite beam element with bonding interface. In displacement-based finite element (FE) formulation, three damage indicators have been embedded into stiffness matrix of the composite beam that are defined as a stiffness reduction in the concrete, steel and interface layers. An algorithm based on recursive quadratic programming has been proposed to identify structural damage in the composite beam from static measurements. The analytical FE model is validated by adapting its static responses in undamaged state with those obtained from an equal experimental model as well as a FE model developed in commercial software ABAQUS. A convergence study is conducted to determine the number of the composite beam FEs. To verify the proposed method, the static responses of the FE model with different damage cases at a given loading are calculated, and the measurements are simulated by adding different levels of white noise. Then, the proposed algorithm is applied to identify damage of the composite beam. The effects of measurement noise, loading location and amplitude, measurement numbers and the sizes of FE mesh on the identified results have been investigated. The numerical results show that this method is efficient and accurate to separately identify small damage in the concrete slab, and the steel girder and bonding interface of the composite beam.
\end{abstract}

Keywords: Composite structures, Damage identification, Shear connection, Steel-concrete composite element, Static measurements

\section{Introduction}

In the recent decades, the research on structural damage identification has attracted great deal of attention. During this time, many methods have been developed using dynamic and static measurements, so depending on the different measurements, these methods can be categorized into dynamic and static approaches. Unlike the static identification methods, the dynamic methods have been studied more extensively because they are easy to implement [1-5]. Structural modal parameters such as natural frequencies, mode shapes and modal damping are functions of physical parameters such as mass, damping and stiffness [6, 7], and while damage can change the damping and mass distribution of a structure, these changes are ignored in the dynamic identification analysis for simplification. Furthermore, the damage is a local phenomenon and the high frequency component is much more sensitive to the damage, however it is difficult to extract the accurate high frequency component in a noisy environment. The static identification methods are based on equilibrium equations so the only significant parameters are the stiffness properties of a structure; therefore, the stiffness reduction is an important parameter when identifying the effects that structural damage has on the static responses. A large number of static measurements are generally required to obtain accurate damage identification, but this is not economically feasible. Choi et al [8] showed that this issue can be tackled by increasing the loading conditions instead of increasing the measurement numbers. Zhang et al [9] proposed a method for using the optimal numbers of strain gages and displacements sensors together. They 
claimed that using integrated sensor system gives better result in contrast to single type sensors. With current advances in non-contact deflection measurement technology, the static approach has become much more interesting $[10,11]$.

Over the past few decades, different static damage identification methods have been developed using simple structures such as truss, frame or beam-like structures. Zhu et al [12] proposed a displacement-based damage identification algorithm for reinforced concrete beams by incorporating the interface element into the FE formulation. Raghuprasad et al [13] presented an approach for identifying damage of a bridge girder subjected to loads at two symmetric points, using static deflection as the damage indicator. Li et al [14] developed a relative displacement sensor for damage identification of girder-slab composite bridges with bonding slip. Caddemi et al [15] proposed a method for identifying open cracks in beams and frame using static measurements. More recently, Le et al [16] proposed a new approach for locating and quantifying damage in Euler-Bernoulli beams using static responses. However, a three-layer composite beam considering partial shear connection has not been studied. The damage assessment of these composite layers alone is a significant issue and in particular, the inaccessible shear connectors that effect on the composite behaviour under loading. Therefore, this study aims to develop a steel-concrete composite element with bonding interface for the structural damage identification from static measurements. A new damage algorithm is then proposed based on damage indicators embedded into stiffness matrices and the composite beam responses, in the undamaged and damaged states.

Steel-concrete composite structures are widely investigated by many researchers due to complicated interconnection of the composite layers. Dynamic behaviour of the steel-concrete composite beams with partial shear interaction was studied by $[17,18]$. In both studies, they highlighted the effect of bonding slip on the response of the composite beams. A notable research was established by Ayoub and Filippou [19] presenting an inelastic beam element for analysing a steel-concrete composite beam with partial interaction under cyclic loading. The shear connection is accounted for an interface model with a distributed force. Chen et al [20] studied the static behaviour of steel-concrete composite beams where the shear connectors had been damaged due to corrosion. Their experimental test results indicated that corrosion of studs has a significant effect on beam stiffness and the load bearing capacity. The behaviour of two-layers composite beams are affected by both the interface longitudinal slip and vertical uplift. However, the bonding slip has been significantly considered in this research topic while the vertical uplift is negligible due to small displacements $[21,22]$. So far, existing research in steel-concrete composite members has mostly focused on the design aspects of bonding slip and shear connectors [23-25]. However, the damage identification of steelconcrete composite beam-type elements is a critical issue because the contribution made by the bonding stiffness in global stiffness matrices of the composite beam element is smaller [12]; this leads to an intricate interconnection between the composite layers and therefore a robust method of identification is needed.

In this paper, an innovative method based on displacement-based finite element (FE) modelling is proposed to identify the damage in steel-concrete composite structures. A steel-concrete composite element with a bonding interface has been developed, and the concrete and steel layers are independently interpolated into a displacement-based finite element (FE) formulation. Three damage indices are defined to describe the stiffness reduction of a concrete slab, a steel girder and the bonding interface. These damage indicators are incorporated into the stiffness matrix of composite beam. The recursive quadratic programming (RQP) algorithm is used to solve the optimization problem for structural damage identification from static measurements. To validate the FE model, its static responses in undamaged state are adapted with those obtained from an equal experimental model as well as a FE model developed in commercial software ABAQUS [26]. Then, the proposed algorithm is used to identify damage from the static responses of the FE model. White noise is added to the calculated responses to simulate the measurements and the effect of measurement noise is studied. The effects of the measurement locations and numbers, type of static parameters and the sizes of FE mesh on the identified results are also discussed. The results show that this method can effectively identify defects in the composite layers and the bonding interface.

\section{Analytical procedure}




\subsection{Basic formulations}

The fundamental equations that govern the two-layered behaviour of a composite beam with deformable shear connector are presented in this section. The effects that the deformable shear connectors have on the behaviour of a composite beam are considered as interface element. A distributed interface element is taken into account for simplification. The aim is to develop displacement-based FE derivations of a composite beam element that consists of two beam elements (concrete slab and steel girder) and an interface element. The composite beam element with 10 degrees of freedom (DOFs) includes 3 axial displacements for the concrete slab $\boldsymbol{u}_{c}=\left[\begin{array}{lll}u_{c 1} & u_{c 2} & u_{c 3}\end{array}\right]^{T}$, three axial displacements for the steel girder $\boldsymbol{u}_{\boldsymbol{s}}=\left[\begin{array}{lll}u_{s 1} & u_{s 2} & u_{s 3}\end{array}\right]^{T}$ and, two rotations and two transverse displacements for the composite element $v=\left[\begin{array}{llll}v_{1} & \theta_{1} & v_{2} & \theta_{2}\end{array}\right]^{T}$.

A composite beam element consists of a concrete slab located on top of a steel girder, and the bonding interfaces are shown in Figure (1.a). For each component of this composite beam, the equilibrium equations with bond slip and uplift effects are formulated [27]. The forces referring to concrete and steel are denoted by the subscripts $c$ and $s . N$ and $V$ denote the axial force and shear force, respectively. $M_{c}$ and $M_{S}$ are the bending moment of concrete and steel, respectively. $D_{s c}$ and $D_{t}$ are the shear force (bonding slip) and the transverse force (uplift) per unit length. $P$ is the external distributed load per unit length applied perpendicular to the concrete slab. $h_{c}$ and $h_{s}$ are the distances between the interface and reference axes of the concrete slab and steel girder, respectively. The equilibrium equation of the composite beam section can be defined as [19]

(a)
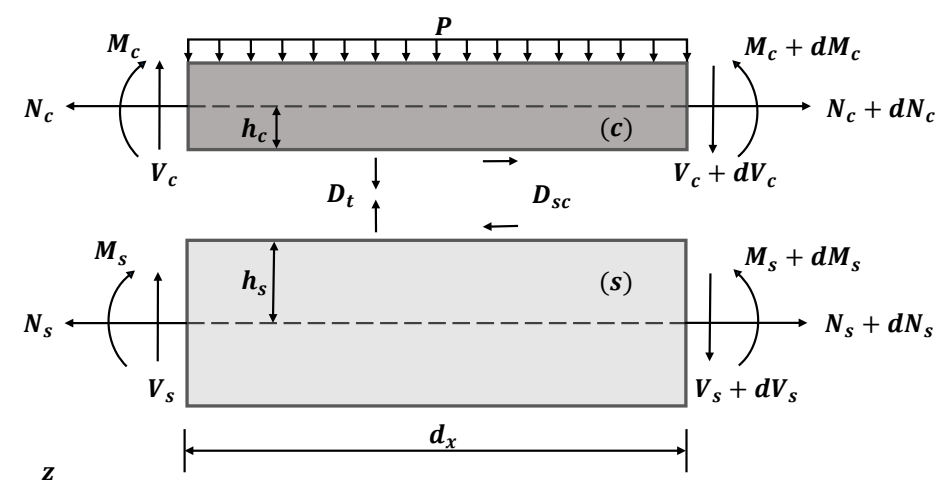

(b)

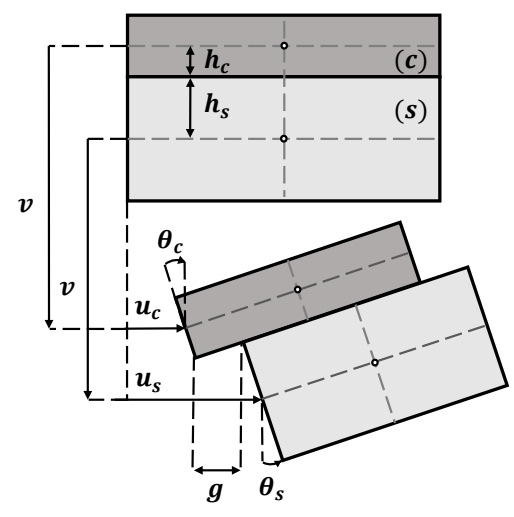

Figure 1. (a) Diagram and (b) Kinematic of two-layer composite beam element; $c$ and s denotes concrete and steel layers, respectively

$$
\partial^{T} \boldsymbol{F}(x)-\partial_{b}^{T} \boldsymbol{F}_{b}(x)-\boldsymbol{P}(\boldsymbol{x})=0
$$

in which $\boldsymbol{F}(x)=\left[\begin{array}{lll}N_{c} & N_{s} & M\end{array}\right]^{T}, \boldsymbol{F}_{b}(x)=\left[\begin{array}{ll}D_{s c}\end{array}\right]$ and $\boldsymbol{P}(x)=\left[\begin{array}{lll}0 & 0 & P\end{array}\right]^{T}$ are the internal forces vector acting on the cross section, the interface bonding force and the vector of the external load, respectively.

Furthermore, the differential operators, $\partial$ and $\partial_{b}$ are given as

$$
\begin{aligned}
& \partial=\left[\begin{array}{ccc}
\partial_{x} & 0 & 0 \\
0 & \partial_{x} & 0 \\
0 & 0 & \partial_{x}^{2}
\end{array}\right] \\
& \partial_{b}=\left[\begin{array}{lll}
1 & -1 & h \partial_{x}
\end{array}\right]
\end{aligned}
$$

Although any section of this composite beam has four unknown forces $N_{c}, N_{s}, M$ and $D_{s c}$, there are only three equations of equilibrium for each section. Therefore, to tackle the indeterminacy of the composite beam, compatibility equations must be added to the equilibrium equations. Figure (1.b) shows the kinematics of a two-layer composite beam with bond slip. Since the same transverse displacement (no uplift) has been considered for both layers, the curvature and rotation will be the same. The left and right figures clearly 
show the bond slip and its value between two layers, where $v, u, h, g$ and $\theta$ are the transverse displacement, axial displacement, distance between the centroid axes of concrete and steel, interface slip and rotation, respectively. Different axial deformations can occur in the steel and concrete sections. The axial and transverse deformations at any section of the composite beam are handled by the compatibility conditions based on the Euler-Bernoulli beam theory. The compatibility conditions are treated for the concrete slab and steel girder components subjected to a small displacement. The composite beam section displacements are assembled in a vector where $\boldsymbol{u}(x)=\left[\begin{array}{lll}u_{c}(x) & u_{s}(x) & v(x)\end{array}\right]^{T}$, in which $u(x)$ and $v(x)$ are the axial and transverse displacements, respectively. The section deformations are also presented as a vector where $\boldsymbol{d}(x)=\left[\begin{array}{lll}\varepsilon_{c}(x) & \varepsilon_{s}(x) & \kappa(x)\end{array}\right]^{T}$, in which $\varepsilon_{c}(x)=\partial_{x} u_{c}(x)$ is the concrete slab axial strain, $\varepsilon_{s}(x)=\partial_{x} u_{s}(x)$ is the steel girder axial strain and $\kappa(x)=\partial_{x}^{2} v(x)$ is the curvature [19].

The compatibility conditions define the deformation and displacement at the interface between the concrete slab and steel girder. This relative displacement at the interface is known as the bond slip $g$ and can be defined as;

$$
g=u_{c}(x)-u_{s}(x)+h \partial_{x} v(x)
$$

Eq. (4) can be written in the form of matrices as follows:

$$
\left[\begin{array}{ccc}
\partial_{x} & 0 & 0 \\
0 & \partial_{x} & 0 \\
0 & 0 & \partial_{x}^{2} \\
1 & -1 & h \partial_{x}
\end{array}\right]\left[\begin{array}{c}
u_{c} \\
u_{s} \\
v
\end{array}\right]-\left[\begin{array}{c}
\varepsilon_{c} \\
\varepsilon_{s} \\
\kappa \\
g
\end{array}\right]=\left[\begin{array}{l}
0 \\
0 \\
0 \\
0
\end{array}\right]
$$

Eq. (5) can be separated into the section deformation $\boldsymbol{d}(x)=\partial \boldsymbol{u}(x)$ and bond deformation $\boldsymbol{d}_{\boldsymbol{b}}(x)=$ $\partial_{b} \boldsymbol{u}(x)$. Eqs. (1) and (4) are the equilibrium and compatibility relations and the material constitutive laws for a steel-concrete composite beam element. The response of the composite beam subjected to external loads can be obtained with proper boundary conditions. Then the sectional and elemental stiffness matrices of the composite element for structural damage identification are derived in Section 2.2.

\subsection{Stiffness matrix of the steel-concrete composite element}

Three different stiffness matrices are presented for the concrete and steel beam components and bonding interface. These matrices are exploited to obtain the local and global matrices of the composite beam element. The interface element is assumed to be a continuous spring element with particular stiffness parameters. In order to estimate the displacements of the composite beam, quadratic polynomial functions are used for the axial displacements and cubic Hermitian polynomials are used for the transverse displacements [28]. To permit the quadratic polynomials for the axial displacements, two extra nodes (DOFs) are introduced separately in the middle of each element (concrete slab and steel girder). These provide a continuous quadratic bond slip condition along the interface. The same transverse displacement are considered for both layers (no uplift) and therefore, the steel-concrete composite beam element with bond slip in the interface connection consists of ten DOFs including two transverses and rotations, and six axial displacements (Figure 2). $\boldsymbol{U}=\left[\begin{array}{llllllllll}u_{c 1} & u_{c 2} & u_{c 3} & u_{s 1} & u_{s 2} & u_{s 3} & v_{1} & \theta_{1} & v_{2} & \theta_{2}\end{array}\right]^{T}$ is the vector of the elemental nodal displacements.

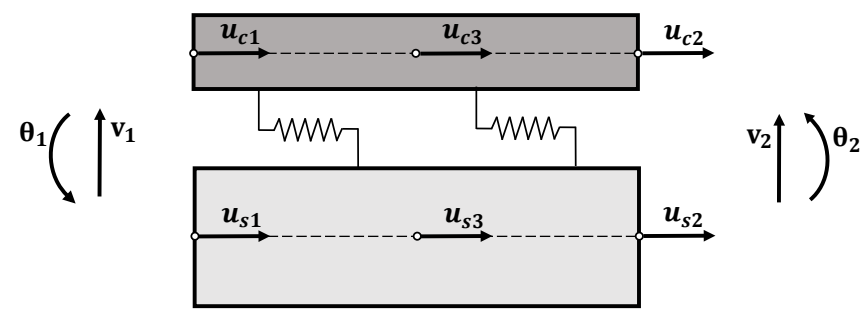

Figure 2. Nodal displacements of a steel-concrete composite element with 10 DOF 
The internal forces of the composite beam are related to the deformation, and the interface bonding force is related to the bond slip. Therefore, the force-deformation relationships for a linear-elastic steel-concrete composite beam are defined by the material properties and cross sectional geometry of the beam as

$$
\begin{aligned}
& \boldsymbol{F}_{c}(x)=\boldsymbol{k}_{c} \boldsymbol{d}_{c}(x) \\
& \boldsymbol{F}_{\boldsymbol{s}}(x)=\boldsymbol{k}_{s} \boldsymbol{d}_{s}(x) \\
& \boldsymbol{F}_{b}(x)=\boldsymbol{k}_{b} \boldsymbol{d}_{b}(x)
\end{aligned}
$$

where $\boldsymbol{F}_{c}(x)$ and $\boldsymbol{F}_{S}(x)$ are the internal force vectors for concrete and steel sections, respectively; $\boldsymbol{d}_{c}(x)$ and $\boldsymbol{d}_{s}(x)$ are the concrete and steel sections deformation vectors, respectively. $\boldsymbol{k}_{c}, \boldsymbol{k}_{s}$ and $\boldsymbol{k}_{b}$ are the stiffness matrices of concrete section, steel section and bonding interface, respectively. The stiffness matrices are obtained by the virtual work method. A small displacement caused by the external loads is assumed to occur, and the amount of work is equalled to the amount of residual internal strain energy. Therefore, the sectional stiffness matrices for the concrete and steel sections and the bonding interface are given as below:

$$
\begin{gathered}
\boldsymbol{k}_{c}=\left[\begin{array}{ccc}
k_{c 1} & 0 & k_{c 2} \\
0 & 0 & 0 \\
k_{c 3} & 0 & k_{c 4}
\end{array}\right] \\
\boldsymbol{k}_{s}=\left[\begin{array}{ccc}
0 & 0 & 0 \\
0 & k_{s 1} & k_{s 2} \\
0 & k_{s 3} & k_{s 4}
\end{array}\right] \\
\boldsymbol{k}_{b}=\left[\begin{array}{lll}
k_{b 1} & k_{b 2} & k_{b 3} \\
k_{b 4} & k_{b 5} & k_{b 6} \\
k_{b 7} & k_{b 8} & k_{b 9}
\end{array}\right]
\end{gathered}
$$

where $k_{c 1}=E_{c} A_{c}, k_{c 2}=k_{c 3}=-E_{c} A_{c} h_{c}$ and $k_{c 4}=E_{c} I_{c}, k_{s 1}=E_{s} A_{s}, k_{s 2}=k_{s 3}=-E_{s} A_{s} h_{s}$ and $k_{s 4}=$ $E_{s} I_{s}, k_{b 1}=k_{b 5}=E_{b} W_{b}, k_{b 2}=k_{b 4}=-E_{b} W_{b}, k_{b 3}=k_{b 7}=E_{b} W_{b} h, k_{b 6}=k_{b 8}=-E_{b} W_{b} h$ and $h_{b 9}=$ $E_{b} W_{b} h^{2} . E_{c}, A_{c}$ and $I_{c}$ are the Young's elastic modulus, cross sectional area and moment of inertia of the concrete section, respectively. $E_{s}, A_{s}$ and $I_{s}$ are the Young's elastic modulus, cross-sectional area and moment of inertia of the steel section, respectively. $E_{b}, W_{b}$ and $h$ are equivalent modulus of bonding interface between concrete slab and steel girder, width of the steel top flange (concrete-steel contact length) and the distance between the centroid axes of concrete and steel, respectively. For a linear-elastic composite beam with bond slip, the vector of shape functions can be written as

$$
\begin{aligned}
& \boldsymbol{Q}_{u_{c}}=\left[\begin{array}{lll}
Q_{u_{c 1}} & Q_{u_{c 2}} & Q_{u_{c 3}}
\end{array}\right] \\
& \boldsymbol{Q}_{u_{s}}=\left[\begin{array}{lll}
Q_{u_{s 1}} & Q_{u_{s 2}} & Q_{u_{s 3}}
\end{array}\right] \\
& \boldsymbol{Q}_{v}=\left[\begin{array}{llll}
Q_{v_{1}} & Q_{\theta_{1}} & Q_{v_{2}} & Q_{\theta_{2}}
\end{array}\right]
\end{aligned}
$$

where $\boldsymbol{Q}_{u_{c}}$ is the vector of the axial displacements shape functions $Q_{u_{1}}, Q_{u_{2}}$ and $Q_{u_{3}}, \boldsymbol{Q}_{u_{s}}$ is the vector of the axial displacements shape functions $Q_{u_{s 1}}, Q_{u_{s 2}}$ and $Q_{u_{s 3}}$ and $\boldsymbol{Q}_{v}$ is the vector of the transverse displacements and rotations shape functions $Q_{v_{1}}, Q_{v_{2}}, Q_{\theta_{1}}$ and $Q_{\theta_{2}}$. These shape functions interpolate the discrete values obtained at the FE nodes. The elemental stiffness matrices are obtained by integrating the sectional stiffness matrices in terms of the displacement shape functions as follows

$$
\begin{aligned}
& \boldsymbol{K}_{e c}=\left[\begin{array}{ccc}
\int_{0}^{L} \dot{\boldsymbol{Q}}_{u_{c}}^{T} k_{c 1} \dot{\boldsymbol{Q}}_{u_{c}} d x & \mathbf{0} & -\int_{0}^{L} \dot{\boldsymbol{Q}}_{u_{c}}^{T} k_{c 2} \ddot{\boldsymbol{Q}}_{v} d x \\
\mathbf{0} & \mathbf{0} & \mathbf{0} \\
-\int_{0}^{L} \ddot{\boldsymbol{Q}}_{v}^{T} k_{c 3} \dot{\boldsymbol{Q}}_{u_{c}} d x & \mathbf{0} & \int_{0}^{L} \ddot{\boldsymbol{Q}}_{v}^{T} k_{c 4} \ddot{\boldsymbol{Q}}_{v} d x
\end{array}\right]_{10 \times 10} \\
& \boldsymbol{K}_{e s}=\left[\begin{array}{ccc}
\mathbf{0} & \mathbf{0} & \mathbf{0} \\
\mathbf{0} & \int_{0}^{L} \dot{\boldsymbol{Q}}_{u_{s}}^{T} k_{s 1} \dot{\boldsymbol{Q}}_{u_{s}} d x & -\int_{0}^{L} \dot{\boldsymbol{Q}}_{u_{s}}^{T} k_{s 2} \ddot{\boldsymbol{Q}}_{v} d x \\
\mathbf{0} & -\int_{0}^{L} \ddot{\boldsymbol{Q}}_{v}^{T} k_{s 3} \dot{\boldsymbol{Q}}_{u_{s}} d x & \int_{0}^{L} \ddot{\boldsymbol{Q}}_{v}^{T} k_{s 4} \ddot{\boldsymbol{Q}}_{v} d x
\end{array}\right]_{10 \times 10} \\
& \boldsymbol{K}_{e b}=\left[\begin{array}{ccc}
\int_{0}^{L} \boldsymbol{Q}_{u_{c}}^{T} k_{b 1} \boldsymbol{Q}_{u_{c}} d x & -\int_{0}^{L} \boldsymbol{Q}_{u_{c}}^{T} k_{b 2} \boldsymbol{Q}_{u_{s}} d x & \int_{0}^{L} \boldsymbol{Q}_{u_{c}}^{T} k_{b 3} \dot{\boldsymbol{Q}}_{v} d x \\
-\int_{0}^{L} \boldsymbol{Q}_{u_{s}}^{T} k_{b 2} \boldsymbol{Q}_{u_{c}} d x & \int_{0}^{L} \boldsymbol{Q}_{u_{s}}^{T} k_{b 1} \boldsymbol{Q}_{u_{s}} d x & -\int_{0}^{L} \boldsymbol{Q}_{u_{s}}^{T} k_{b 3} \dot{\boldsymbol{Q}}_{v} d x \\
\int_{0}^{L} \dot{\boldsymbol{Q}}_{v}^{T} k_{b 7} \boldsymbol{Q}_{u_{c}} d x & -\int_{0}^{L} \dot{\boldsymbol{Q}}_{v}^{T} k_{b 7} \boldsymbol{Q}_{u_{s}} d x & \int_{0}^{L} \dot{\boldsymbol{Q}}_{v}^{T} k_{b 9} \dot{\boldsymbol{Q}}_{v} d x
\end{array}\right]_{10 \times 10}
\end{aligned}
$$


where $\boldsymbol{K}_{e c}, \boldsymbol{K}_{e s}$ and $\boldsymbol{K}_{e b}$ are the element stiffness matrices of concrete, steel and bonding interface, respectively. Therefore, the stiffness matrix of the composite beam element is obtained by the summation of three elements given as:

$$
\boldsymbol{K}_{e}=\boldsymbol{K}_{e c}+\boldsymbol{K}_{e s}+\boldsymbol{K}_{e b}=\left[\begin{array}{lll}
{\left[\boldsymbol{K}_{e 1}\right]_{3 \times 3}} & {\left[\boldsymbol{K}_{e 2}\right]_{3 \times 3}} & {\left[\boldsymbol{K}_{e 3}\right]_{3 \times 4}} \\
{\left[\boldsymbol{K}_{e 4}\right]_{3 \times 3}} & {\left[\boldsymbol{K}_{e 5}\right]_{3 \times 3}} & {\left[\boldsymbol{K}_{e 6}\right]_{3 \times 4}} \\
{\left[\boldsymbol{K}_{e 7}\right]_{4 \times 3}} & {\left[\boldsymbol{K}_{e 8}\right]_{4 \times 3}} & {\left[\boldsymbol{K}_{e 9}\right]_{4 \times 4}}
\end{array}\right]_{10 \times 10}
$$

where $\boldsymbol{K}_{e}$ is the steel-concrete composite element stiffness matrix.

\subsection{Elemental damage indicators}

The damage of the composite structure is defined as three damage indicators that correspond to the reduction in elemental stiffness of the concrete, the steel beams and the interface bonding. The bonding force distributed between the steel and concrete components can be expressed as

$$
\Delta N=\int_{0}^{L} F_{b}(x) d x
$$

where $\Delta N$ is the bonding force and $L$ is the length of the beam element. The relationship between the bonding force and bonding slip in a composite beam element can be defined as

$$
\Delta N=K_{e b} \Delta \boldsymbol{U}_{b}=E_{b} W_{b} \Delta U_{b}
$$

where $\Delta \boldsymbol{U}_{b}$ is the difference between the vector of analytical displacements of interface before and after damage. From Eqs. (17) and (18), the equivalent bonding stiffness can be written as

$$
K_{e b}=E_{b} W_{b}=\frac{\int_{0}^{L} F_{b}(x) d x}{\Delta U_{b}}
$$

In these above equations, a damage index is introduced based on the degradation in the stiffness characteristic of the boning interface as

$$
\alpha_{b}=1-\frac{K_{e b}}{\widehat{K}_{e b}}=1-\frac{E_{b}}{\widehat{E}_{b}}
$$

where $\widehat{K}_{e b}$ is the equivalent bonding stiffness without damage or slippage $\widehat{E}_{b}$ is the equivalent modulus of bonding interface between the concrete slab and steel girder without damage or slippage, and $\alpha_{b}$ is the damage index parameter for the interface element. By using a similar approach, the damage indices for the concrete and steel elements are defined as follow

$$
\begin{aligned}
& \alpha_{c}=1-\frac{E_{c}}{\hat{E}_{c}} \\
& \alpha_{s}=1-\frac{E_{s}}{\hat{E}_{s}}
\end{aligned}
$$

where $\hat{E}_{c}$ is the equivalent Elastic modulus of the intact concrete element, $\hat{E}_{s}$ is the equivalent Elastic modulus of the undamaged steel element, and $\alpha_{c}$ and $\alpha_{s}$ are the damage index parameters for the concrete and steel elements, respectively. In any case, when the damage indices are equal to zero, it means there is no damage in that element $\left(0 \ll \alpha_{c}, \alpha_{s}, \alpha_{b} \ll 1\right)$. Since damaged composite element components have been assumed, Eq (22) can be updated using the damage indicators as

$$
\boldsymbol{K}_{e}=\boldsymbol{K}_{e c}+\boldsymbol{K}_{e s}+\boldsymbol{K}_{e b}=\left(1-\alpha_{c}\right) \widehat{\boldsymbol{K}}_{e c}+\left(1-\alpha_{s}\right) \widehat{\boldsymbol{K}}_{e s}+\left(1-\alpha_{b}\right) \widehat{\boldsymbol{K}}_{e b}
$$

where $\widehat{\boldsymbol{K}}_{e c}$ and $\widehat{\boldsymbol{K}}_{e s}$ are the stiffness matrices of the intact concrete and steel elements, respectively. The damage indices $\alpha_{c}, \alpha_{s}$ and $\alpha_{b}$ are considered separately as scalar values embedded in the elemental damage indices zero vectors with a size equal to the composite element FE numbers. Eq. (23) is a local stiffness matrix and must be transformed to the global stiffness matrix using a transformation matrix as:

$\boldsymbol{K}=\boldsymbol{K}_{c}+\boldsymbol{K}_{s}+\boldsymbol{K}_{b}=\sum_{i=1}^{n} \boldsymbol{T}^{T} K_{e i} \boldsymbol{T}=\sum_{i=1}^{n} \boldsymbol{T}^{T} \boldsymbol{K}_{e c i} \boldsymbol{T}+\sum_{i=1}^{n} \boldsymbol{T}^{T} \boldsymbol{K}_{e s i} \boldsymbol{T}+\sum_{i=1}^{n} T^{T} \boldsymbol{K}_{e b i} \boldsymbol{T}$ 


$$
=\sum_{i=1}^{n} \boldsymbol{T}^{T}\left(1-\alpha_{c i}\right) \widehat{\boldsymbol{K}}_{e c i} \boldsymbol{T}+\sum_{i=1}^{n} \boldsymbol{T}^{T}\left(1-\alpha_{s i}\right) \widehat{\boldsymbol{K}}_{e s i} \boldsymbol{T}+\sum_{i=1}^{n} \boldsymbol{T}^{T}\left(1-\alpha_{b i}\right) \widehat{\boldsymbol{K}}_{e b i} \boldsymbol{T}
$$

where $n$ is the number of FEs. $\boldsymbol{K}, \boldsymbol{K}_{c}, \boldsymbol{K}_{s}$ and $\boldsymbol{K}_{b}$ are the global stiffness matrices of the damaged composite beam, concrete, steel and interface elements. $\alpha_{c i}, \alpha_{s i}$ and $\alpha_{b i}$ are the $i$ th element damage indices of damaged concrete, steel and bonding interface, respectively. $\boldsymbol{T}$ is the transformation matrix of element nodal displacement that assembles the global stiffness matrix form of the elemental local stiffness matrix.

\section{Structural damage identification using static measurements}

A damage algorithm is proposed for the local damage detection of steel-concrete composite structures by incorporating bonding slip. For a damaged structure, the force-displacement equation can be defined as

$$
\boldsymbol{F}=\boldsymbol{K} \boldsymbol{U}
$$

where $\boldsymbol{F}$ is the force vector, $\boldsymbol{K}$ is the stiffness matrix of the damaged composite beam element and $\boldsymbol{U}$ is the vector of the nodal displacements and rotations. The discrepancy between intact and damaged states in terms of stiffness and displacement can be expressed as

$$
\begin{gathered}
\Delta \boldsymbol{K}=\widehat{\boldsymbol{K}}-\boldsymbol{K} \\
\Delta \boldsymbol{U}=\widehat{\boldsymbol{U}}-\boldsymbol{U}
\end{gathered}
$$

where $\Delta \boldsymbol{U}$ is the difference between the vector of analytical displacements before and after damage, $\Delta \boldsymbol{K}$ is the stiffness matrix difference of the structure with and without damage, $\widehat{\boldsymbol{K}}$ and $\widehat{\boldsymbol{U}}$ are the stiffness matrix and displacement of the composite beam in an undamaged state, respectively, and $\boldsymbol{K}$ and $\boldsymbol{U}$ are the stiffness matrix and displacement of the damaged composite beam, respectively. By substituting Eqs. (26) and (27) into (25), the force vector can be represented as

$$
\boldsymbol{F}=(\widehat{\boldsymbol{K}}-\Delta \boldsymbol{K})(\widehat{\boldsymbol{U}}-\Delta \boldsymbol{U})
$$

$\Delta \boldsymbol{U}$ can be obtained from Eq. (27) as

$$
\begin{aligned}
\Delta \boldsymbol{U}= & \widehat{\boldsymbol{K}}^{-1} \Delta \boldsymbol{K} \widehat{K}^{-1} \boldsymbol{F}+\widehat{\boldsymbol{K}}^{-1} \Delta \boldsymbol{K} \Delta \boldsymbol{U} \approx \widehat{\boldsymbol{K}}^{-1} \Delta \boldsymbol{K} \widehat{\boldsymbol{K}}^{-1} \boldsymbol{F} \\
& =\widehat{\boldsymbol{K}}^{-1} \Delta \boldsymbol{K}_{\boldsymbol{c}} \widehat{\boldsymbol{K}}^{-1} \boldsymbol{F}+\widehat{\boldsymbol{K}}^{-1} \Delta \boldsymbol{K}_{s} \widehat{\boldsymbol{K}}^{-1} \boldsymbol{F}+\widehat{\boldsymbol{K}}^{-1} \Delta \boldsymbol{K}_{b} \widehat{\boldsymbol{K}}^{-1} \boldsymbol{F}
\end{aligned}
$$

where $\Delta \boldsymbol{K}_{c}=\sum_{i=1}^{n} \boldsymbol{T}^{T} \alpha_{c i} \widehat{\boldsymbol{K}}_{e c i} \boldsymbol{T}, \Delta \boldsymbol{K}_{s}=\sum_{i=1}^{n} \boldsymbol{T}^{T} \alpha_{s i} \widehat{\boldsymbol{K}}_{e s i} \boldsymbol{T}$ and $\Delta \boldsymbol{K}_{b}=\sum_{i=1}^{n} \boldsymbol{T}^{T} \alpha_{b i} \widehat{\boldsymbol{K}}_{e b i} \boldsymbol{T}$. The following relation can be obtained by substituting Eq. (16) into Eq. (29)

$$
\begin{aligned}
\Delta \boldsymbol{U}= & \sum_{i=1}^{n} \widehat{\boldsymbol{K}}^{-1} \boldsymbol{T}^{T} \alpha_{c i} \widehat{\boldsymbol{K}}_{e c i} \boldsymbol{T} \widehat{\boldsymbol{K}}^{-1} \boldsymbol{F}+\sum_{i=1}^{n} \widehat{\boldsymbol{K}}^{-1} \boldsymbol{T}^{T} \alpha_{s i} \widehat{\boldsymbol{K}}_{e s i} \boldsymbol{T} \widehat{\boldsymbol{K}}^{-1} \boldsymbol{F}+\sum_{i=1}^{n} \widehat{\boldsymbol{K}}^{-1} \boldsymbol{T}^{T} \alpha_{b i} \widehat{\boldsymbol{K}}_{e b i} \boldsymbol{T} \widehat{\boldsymbol{K}}^{-1} \boldsymbol{F} \\
& =\sum_{i=1}^{n} \alpha_{c i} \widehat{\boldsymbol{K}}_{c i}+\sum_{i=1}^{n} \alpha_{s i} \widehat{\boldsymbol{K}}_{s i}+\sum_{i=1}^{n} \alpha_{b i} \widehat{\boldsymbol{K}}_{b i}
\end{aligned}
$$

where $\widehat{\boldsymbol{K}}_{c i}=\widehat{\boldsymbol{K}}^{-1} \boldsymbol{T}^{T} \widehat{\boldsymbol{K}}_{e c i} \boldsymbol{T} \widehat{\boldsymbol{K}}^{-1} \boldsymbol{F}, \widehat{\boldsymbol{K}}_{s i}=\widehat{\boldsymbol{K}}^{-1} \boldsymbol{T}^{T} \widehat{\boldsymbol{K}}_{e s i} \boldsymbol{T} \widehat{\boldsymbol{K}}^{-1} \boldsymbol{F}$ and $\widehat{\boldsymbol{K}}_{b i}=\widehat{\boldsymbol{K}}^{-1} \boldsymbol{T}^{T} \widehat{\boldsymbol{K}}_{e b i} \boldsymbol{T} \widehat{\boldsymbol{K}}^{-1} \boldsymbol{F}$. In practice, there are only a limited number of measurements available. These measurements are as follows

$$
\boldsymbol{U}_{m}=\boldsymbol{B} \boldsymbol{U}
$$

where $\boldsymbol{U}_{m}$ is the vector of measured responses, $\boldsymbol{B}$ is the Boolean matrix and $\boldsymbol{U}$ is the vector of displacements. An error is defined based on the differences of the analytical and measured displacement vectors of the structure before and after damage as follows

$$
e\left(\boldsymbol{\alpha}_{c}, \boldsymbol{\alpha}_{s}, \boldsymbol{\alpha}_{b}\right)=\boldsymbol{B} \Delta \boldsymbol{U}-\Delta \boldsymbol{U}_{m}
$$

in which $\Delta \boldsymbol{U}_{m}$ is the discrepancy of the measured displacements of the structure from intact to damaged states. The proposed algorithm is derived by the minimization of a least square function [29] in Eq. (32) as given

$$
\begin{aligned}
& J\left(\boldsymbol{\alpha}_{c}, \boldsymbol{\alpha}_{s}, \boldsymbol{\alpha}_{b}\right)=\frac{1}{2} \sum_{i=1}^{n}\left\|e\left(\boldsymbol{\alpha}_{c}, \boldsymbol{\alpha}_{s}, \boldsymbol{\alpha}_{b}\right)\right\|^{2} \\
& =\frac{1}{2}\left\|\sum_{i=1}^{n} \alpha_{c i} \boldsymbol{B} \widehat{\boldsymbol{K}}_{c i}+\sum_{i=1}^{n} \alpha_{s i} \boldsymbol{B} \widehat{\boldsymbol{K}}_{s i}+\sum_{i=1}^{n} \alpha_{b i} \boldsymbol{B} \widehat{\boldsymbol{K}}_{b i}-\Delta \boldsymbol{U}_{m}\right\|^{2}
\end{aligned}
$$


where $e$ is the Euclidean norm, $0 \ll \alpha_{c i}, \alpha_{s i}, \alpha_{b i} \ll 1$ and $i=1,2, \ldots, n$. Banan et al [30,31] employed the recursive quadratic programming (RQP) method to solve the least square minimization function. In this study, this method has been employed to solve the Eq. (33) problem that leads to determining the damage indicators as

$$
J(\boldsymbol{\alpha})=\frac{1}{2} \boldsymbol{\alpha}^{T} \widehat{\boldsymbol{K}} \boldsymbol{\alpha}-\Delta \boldsymbol{U}_{m}^{T} \widehat{\boldsymbol{K}} \boldsymbol{\alpha}+\frac{1}{2} \Delta \boldsymbol{U}_{m}^{T} \Delta \boldsymbol{U}_{m}=J J(\boldsymbol{\alpha})+\frac{1}{2} \Delta \boldsymbol{U}_{m}^{T} \Delta \boldsymbol{U}_{m}
$$

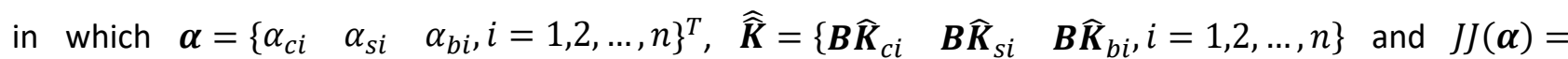
$\frac{1}{2} \boldsymbol{\alpha}^{\boldsymbol{T}} \widehat{\boldsymbol{K}} \boldsymbol{\alpha}-\Delta \boldsymbol{U}_{m}^{T} \widehat{\boldsymbol{K}} \boldsymbol{\alpha}$. Eq. (34) is the proposed algorithm and must be updated for the different damage scenarios. In a case with one type of damage, Eq. (32) can be represented as

$$
e\left(\boldsymbol{\alpha}_{c, b, s}\right)=\boldsymbol{B} \Delta \boldsymbol{U}-\Delta \boldsymbol{U}_{m}=\boldsymbol{B} \sum_{i=1}^{n} \alpha_{c, b, s i} \widehat{\boldsymbol{K}}_{c, b, s i}-\Delta \boldsymbol{U}_{m}
$$

where the subscript $c, b, s$ denotes using either a concrete slab, a bonding interface or a steel girder, $\boldsymbol{\alpha}_{c, b, s}$ and $\widehat{\boldsymbol{K}}_{c, b, s}$ are the damage indicator and intact stiffness matrix, respectively. The RQP is applied to minimize $J J(\alpha)$ by assuming $\alpha_{0}=\left[\begin{array}{llll}0 & 0 & \ldots & 0\end{array}\right]^{T}$ as the initial value for damage index. The outputs are the damage index vector $\boldsymbol{\alpha}$ obtained from minimizing $J J(\alpha)$ (starting from first the iteration, $r=1$ ), and the value of the objective function (VOB). These damage indices and the VOB are used to define two errors as given:

$$
\begin{aligned}
& E r_{1}=\text { VOB }+\frac{1}{2} \Delta \boldsymbol{U}_{m}^{T} \Delta \boldsymbol{U}_{m} \\
& E r_{2}=\frac{\left\|\boldsymbol{\alpha}_{r+1}-\boldsymbol{\alpha}_{r}\right\|}{\left\|\boldsymbol{\alpha}_{r}\right\|} \times 100 \%
\end{aligned}
$$

in which $E r_{1}$ and $E r_{2}$ represent errors 1 and 2, respectively; $\boldsymbol{\alpha}_{r+1}$ and $\boldsymbol{\alpha}_{r}$ are the damage indices resulting from two consecutive iterations. The problem is solved when both errors are less than the given tolerances of $10^{-20}$ and $10^{-6}$, respectively. Otherwise, let $\boldsymbol{\alpha}_{0}=\boldsymbol{\alpha}_{r+1}$, and repeat the above procedure. Further expansion of the damage algorithm is presented when two types of damage exist concurrently in concrete and steel, concrete and bonding, and steel and bonding. For damage in concrete and steel, Eq. (32) is updated as

$$
e\left(\boldsymbol{\alpha}_{c}, \boldsymbol{\alpha}_{s}\right)=\boldsymbol{B} \Delta \boldsymbol{U}-\Delta \boldsymbol{U}_{m}=\boldsymbol{B}\left[\sum_{i=1}^{n} \alpha_{c i} \widehat{\boldsymbol{K}}_{c i}+\sum_{i=1}^{n} \alpha_{s i} \widehat{\boldsymbol{K}}_{s i}\right]-\Delta \boldsymbol{U}_{m}
$$

When one of damage occurs in bonding and another occurs in concrete or steel, Eq. (32) is expressed as

$$
e\left(\boldsymbol{\alpha}_{c, s}, \boldsymbol{\alpha}_{b}\right)=\boldsymbol{B} \Delta \boldsymbol{U}-\Delta \boldsymbol{U}_{m}=\boldsymbol{B}\left[\sum_{i=1}^{n} \alpha_{c, s i} \widehat{\boldsymbol{K}}_{c, s i}+\sum_{i=1}^{n} \alpha_{b i} \widehat{\boldsymbol{K}}_{b i}\right]-\Delta \boldsymbol{U}_{m}
$$

where the subscript $c, s$ denotes using either concrete or steel. In this case, however, the identification of bonding damage from the abovementioned procedure is not straightforward because the contribution of bonding stiffness is very small in the global stiffness matrix of the composite beam. A multiplier is defined based on the Newton iteration method [32] to normalize the bonding damage indicator gradient $\left\|\alpha_{b i_{r+1}}-\alpha_{b i_{r}}\right\|$, as given:

$$
\beta_{c b, s b}=\frac{\left\|\boldsymbol{B} \sum_{i=1}^{n} \widehat{\boldsymbol{K}}_{c, s i}\right\|}{\left\|\boldsymbol{B} \sum_{i=1}^{n} \widehat{\boldsymbol{K}}_{b i}\right\|}
$$

where subscript $c b, s b$ denote multiplier for the case of concrete and bonding or steel and bonding, respectively. Moreover, in case of simultaneous triple damage, Eq. (32) can be defined as

$$
e\left(\boldsymbol{\alpha}_{c}, \boldsymbol{\alpha}_{s}, \boldsymbol{\alpha}_{b}\right)=\boldsymbol{B} \Delta \boldsymbol{U}-\Delta \boldsymbol{U}_{m}=\boldsymbol{B}\left[\sum_{i=1}^{n} \alpha_{c i} \widehat{\boldsymbol{K}}_{c i}+\sum_{i=1}^{n} \alpha_{s i} \widehat{\boldsymbol{K}}_{s i}+\sum_{i=1}^{n} \alpha_{b i} \widehat{\boldsymbol{K}}_{b i}\right]-\Delta \boldsymbol{U}_{m}
$$

and the aforementioned multiplier in Eq. (40) is expressed as

$$
\beta_{c b s}=\frac{\left\|\boldsymbol{B} \sum_{i=1}^{n} \widehat{\boldsymbol{K}}_{c i}+\boldsymbol{B} \sum_{i=1}^{n} \widehat{\boldsymbol{K}}_{s i}\right\|}{\left\|\boldsymbol{B} \sum_{i=1}^{n} \widehat{\boldsymbol{K}}_{b i}\right\|}
$$

in which the subscript $c, b, s$ indicates a triple damage multiplier.

\section{Results and Discussion}

\subsection{Model validation}


The preliminary aim is to develop a reliable baseline FE model that can represent the real structure of interest. To this end, the FE model of the steel-concrete composite beam is built through numerical modelling in MATLAB based on detailed mathematical formulations presented in Section 2.2. The static responses of this model in terms of different loading locations, bond interactions and damage scenarios are to be used specifically for the damage identification using the proposed algorithm. However, to obtain the baseline model, no damage and bond slip are taken into account for this analysis. This analytical FE model is validated by adapting its maximum displacements with those obtained from the experimental testing as well as a $\mathrm{FE}$ model developed using ABAQUS. The beam models considered for either of $\mathrm{FE}$ and experimental models are equivalent in the geometrical and material properties. The concrete slab length is $6000 \mathrm{~mm}$ with $1000 \mathrm{~mm}$ width and $150 \mathrm{~mm}$ depth. The steel girder used is the standard section 460 UB 74.6 with $6000 \mathrm{~mm}$ length. The values of Young's modulus and density for concrete and steel are $E_{c}=32000 \mathrm{MPa}, \rho_{c}=2700 \mathrm{~kg} / \mathrm{m}^{3}$, $E_{s}=210000 \mathrm{MPa}$ and $\rho_{s}=7800 \mathrm{~kg} / \mathrm{m}^{3}$, respectively. In each model, the beam is subjected to a static load of $P=10000 \mathrm{~N}$ first at the middle of the beam and then at $L / 3$ from the left support, and the displacements are measured from different point along the span. In Figure 3, dash and red colour lines labelled FE-M show the displacements obtained from our developed FE model using MATLAB.
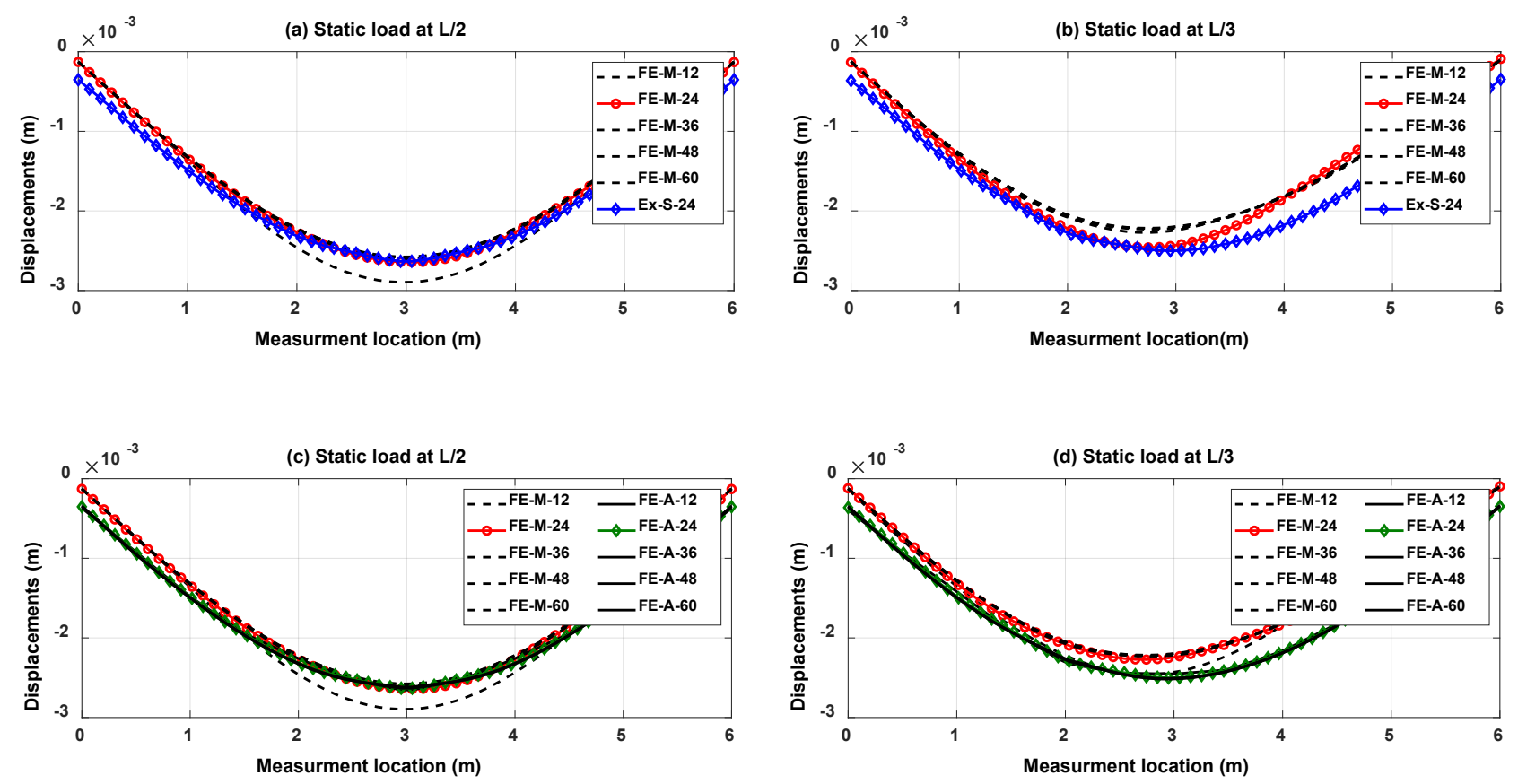

Figure 3. Displacements along the beam obtained from FE modeling in MATLAB (FE-M), ABAQUS (FE-A) and experimental testing (Ex-S)

\section{a) Experimental model}

The structural model used in this study is a simply supported steel-concrete composite beam with a $6000 \mathrm{~mm}$ length from support to support (Figure 4), which has been designed according to Australian Standard [33, 34]. Two layers of steel bars including 4×N12 @ 240mm and 25×N12 @ 240mm in longitudinal and transverse directions, respectively, have been embedded into the concrete slab. The shear connectors are tiered in two lines with $95 \mathrm{~mm}$ spacing and $47.5 \mathrm{~mm}$ offsets from two sides of the steel girder top flange edges. Despite the on-centre spacings between the shear connectors in each line are $460 \mathrm{~mm}$, the total numbers of shear connectors in one line is 14 and in another line is 13 . This is because the end spacings in one line is $110 \mathrm{~mm}$ and another line is $340 \mathrm{~mm}$. Figure 4 shows the composite beam experimental model and the plan view of top flange for the shear connector's alignments. 


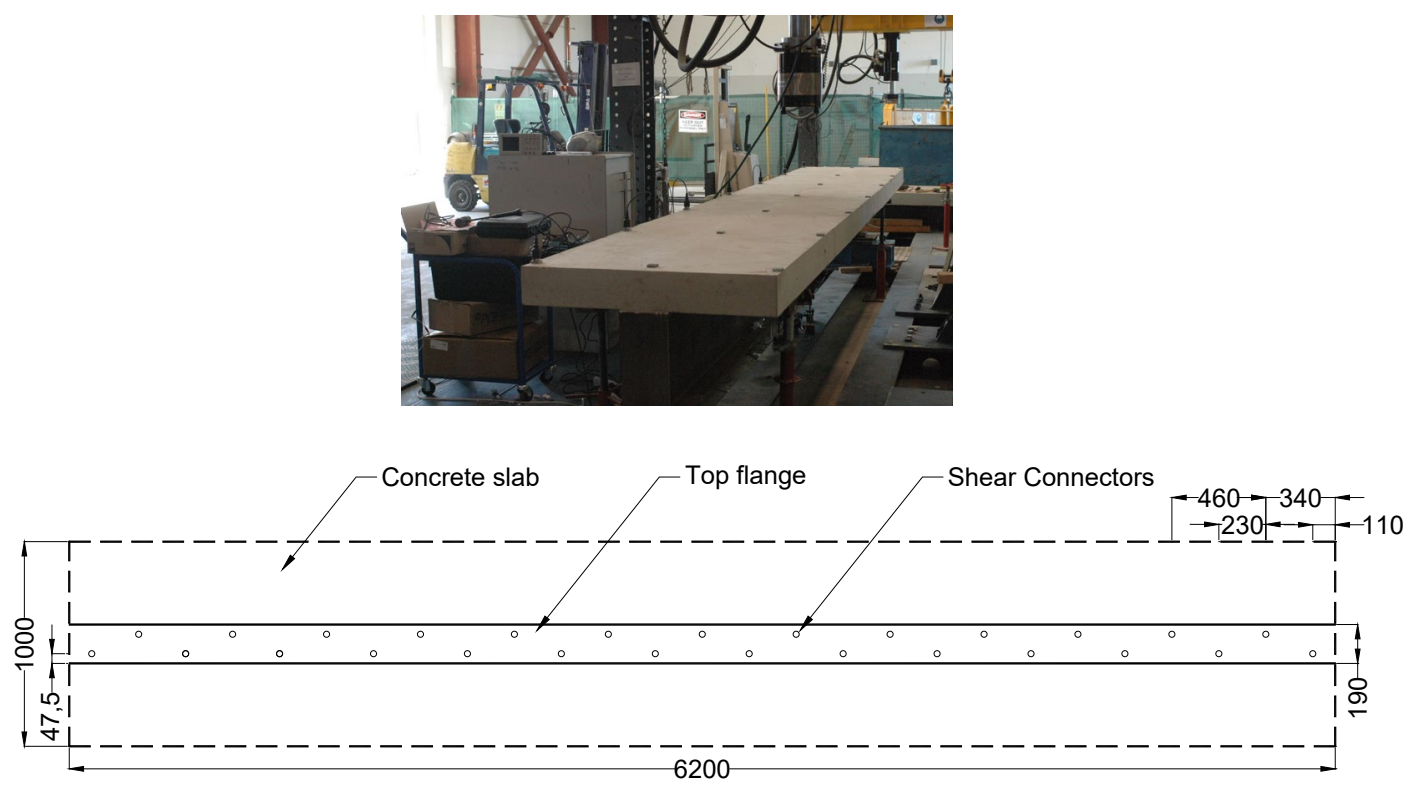

Figure 4. The experimental model (a) steel-concrete composite specimen and (b) top plan view of the specimen showing the shear connector's alignments (length in $\mathrm{mm}$ )

The results obtained from experimental tests have been presented in Figure 3 (labelled as Ex-S), in which blue colour lines show the beam displacement when subjected to static load applied at the middle of span (Figure 3.a) and $L / 3$ from the left support (Figure 3.b). Clearly, there is a very good agreement between our FE model developed using MATLAB (red lines) and our experimental result (blue line).

\section{b) FE model developed using ABAQUS}

A FE model has been developed using commercial software ABAQUS [26] as presented in Figure 5. To simulate the concrete slab and steel girder as composite layers, elastic isotropic solid elements have been used with the aforementioned properties. To model the bonding interface, a zero-thickness cohesive element based on traction separation law $[35,36]$ has been taken into account that is distributed in the interfacial of two layers. This cohesive element is based on the three fracture modes including vertical separation, shear slip and out of plane shear, and for each mode specific stiffness properties are introduced. In Figure 3, black and green colour lines labeled FE-A show the displacements obtained from our developed FE model using ABAQUS.
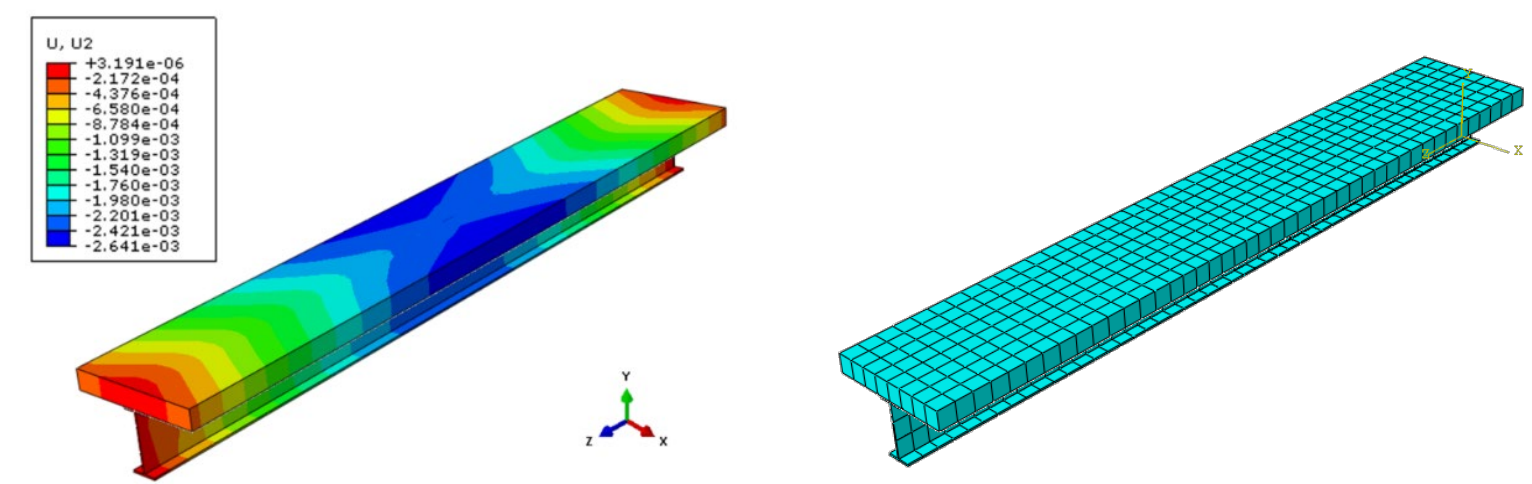

Figure 5. The FE model of steel-concrete composite beam; displacements along the beam subjected to mid-span point load 
For the FE model developed in MATLAB and ABAQUS, different mesh sizes have been considered to enhance the validity of the numerical analysis. In order to conform maximum displacements of two models, the FEs of numerical models have been refined as $12,24,36,48$ and 60 and then the displacements due to the static loadings have been collected. Figure 3 shows the displacements obtained from the FE model developed in MATLAB and their comparison to the results of experimental tests (Figure 3.a and 3.b) and FE model using ABAQUS (Figure 3.c and 3.d). As evidenced in Figure 3 and Table 1, the differences between the maximum displacements for the FE models with 12 FEs are greater than others with smaller mesh sizes. Since the discrepancies after the model with 24 FEs are very small, and the best match with the experimental results is given in the model with $24 \mathrm{FEs}$.

Table 1. Maximum displacements (in $\mathrm{m}$ ) measured from the numerical models in MATLAB (FE-M) and ABAQUS (FE-A), and the experimental model (Ex-S)

\begin{tabular}{|c|c|c|c|c|c|c|}
\hline \multirow{2}{*}{$\begin{array}{l}\text { Measurement } \\
\text { Number of FEs }\end{array}$} & & \multicolumn{5}{|c|}{ Maximum Displacements } \\
\hline & & 12 & 24 & 36 & 48 & 60 \\
\hline \multirow[t]{3}{*}{ Load applied at L/2 } & FE-M & $2.89 \times 10^{-3}$ & $2.64 \times 10^{-3}$ & $2.60 \times 10^{-3}$ & $2.58 \times 10^{-3}$ & $2.57 \times 10^{-3}$ \\
\hline & FE-A & $2.65 \times 10^{-3}$ & $2.64 \times 10^{-3}$ & $2.63 \times 10^{-3}$ & $2.62 \times 10^{-3}$ & $2.61 \times 10^{-3}$ \\
\hline & Ex-S & - & $2.73 \times 10^{-3}$ & - & - & - \\
\hline \multirow[t]{3}{*}{ Load applied at L/3 } & FE-M & $2.46 \times 10^{-3}$ & $2.27 \times 10-3$ & $2.23 \times 10^{-3}$ & $2.22 \times 10^{-3}$ & $2.21 \times 10^{-3}$ \\
\hline & FE-A & $2.45 \times 10^{-3}$ & $2.26 \times 10^{-3}$ & $2.24 \times 10^{-3}$ & $2.21 \times 10^{-3}$ & $2.21 \times 10^{-3}$ \\
\hline & Ex-S & - & $2.32 \times 10^{-3}$ & - & - & - \\
\hline
\end{tabular}

\section{c) Convergence analysis}

In order to obtain an optimal number of FEs for the numerical model, a further study has been carried out in terms of convergence of mesh sizes and static parameters. In Figure 6, the number of FEs has changed from 6 to 60 and the displacement and strain values have been measured. It is shown that while the maximum displacements and strains gradually improved by increments of the number of FEs, there are immediate falling down from models with FE numbers 6 to 20 in both cases. The curves are almost flatted after 24 FEs that are signs for selecting the optimal number of FEs for the model. Therefore, 24 elements are used in the numerical modelling for the damage identification.
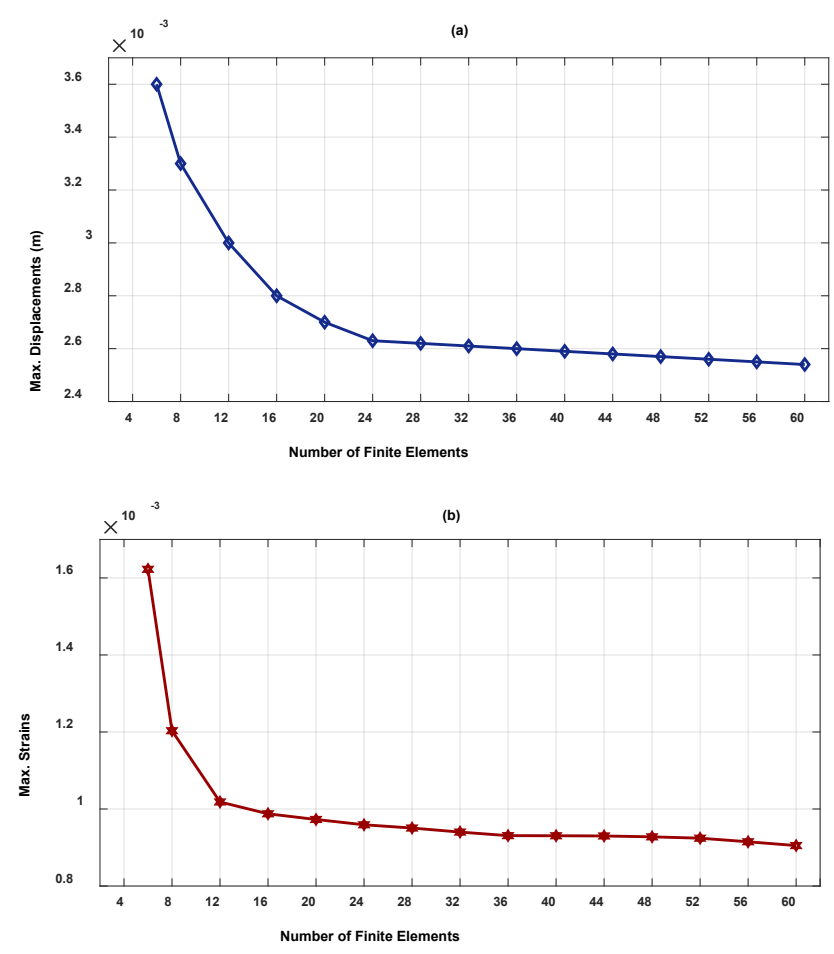
Figure 6. Convergence analysis (a) the maximum displacement and (b) the maximum strain in terms of number of FEs

\subsection{Verification of the proposed method}

The numerical model with $24 \mathrm{FEs}$ of equal size are considered in the FE modelling. Depending on the damage case, the steel-concrete composite beam subjected to a static load $P=10000 \mathrm{~N}$ at $L / 3, L / 2$ and $2 L / 3$ and the static responses are measured from 12, 24 and 48 points spread equally along the length of the beam. Note that the reason for choosing even numbers for measurement is to avoid measurement points exactly on the two-end supports. The analytical responses are simulated by adding the white noise as:

$$
\boldsymbol{u}=\boldsymbol{u}_{a}\left(1+N_{l} N_{n}\right)
$$

in which $\boldsymbol{u}$ is the simulated measurements and $\boldsymbol{u}_{\boldsymbol{a}}$ is the analytical responses. $N_{l}$ and $N_{n}$ are the noise level and the zero mean normally distribution vector, respectively. To determine the reliability of the proposed method, different cases (Figure 7) of single, double and triple damage are introduced by defining the damage index vectors with a size equal to the FE's number of the beam. Table 2 is a summary of different damage cases. First, the effects of measurement noise and loading locations in the single damage case are investigated, and then the sensitivity of static parameters to measurement noise for the bonding case is studied. Following this, sporadic and neighbour damage types are considered for the double damage case, and then triple damage for sporadic damage type is studied in terms of different numbers of measurements and FEs using displacements and strains. It is worth mentioning that in the cases of single and double damage with different noise levels, since it is impossible to identify the true damage index, the results have been compared with the identified results with no measurement noise.

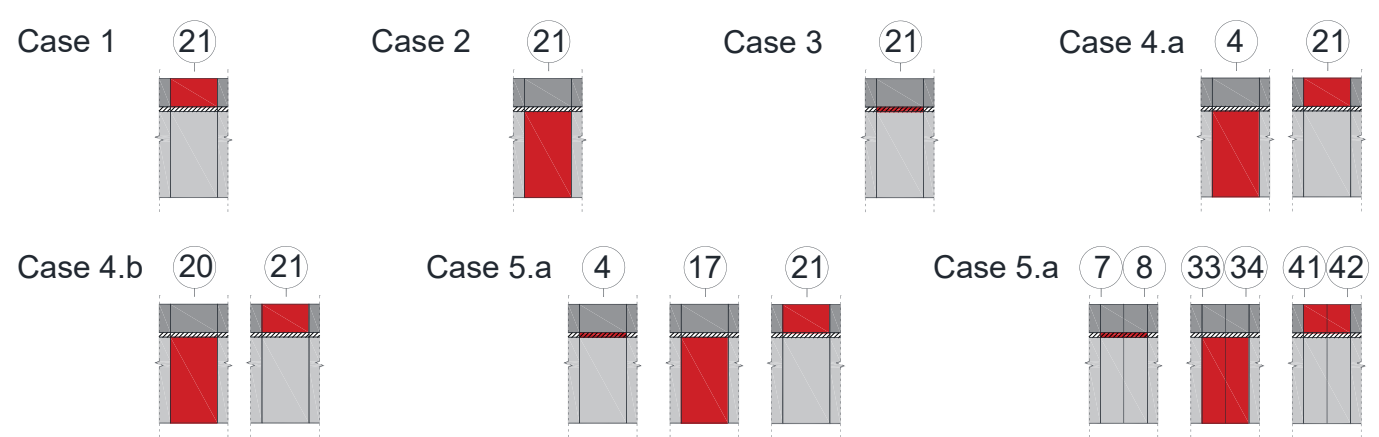

Figure 7. Schematic of the damage cases introduced for different elements; red colour denotes damage on the concrete (top), bonding (middle) and steel (bottom), each FE element number stands in the circle on top

Table 2. The summary of proposed damage cases; D, S and Sp denotes displacement, strain and sporadic, respectively.

\begin{tabular}{|c|c|c|c|c|c|c|}
\hline Cases & Case 1 & Case 2 & Case 3 & Case 4 & Case 5 & \\
\hline Elements & Concrete & Steel & Bonding & $\begin{array}{l}\text { Concrete } \\
\text { Steel }\end{array}$ & $\begin{array}{l}\text { Concrete } \\
\text { Steel } \\
\text { Bonding } \\
\end{array}$ & \\
\hline FEs no. & $\begin{array}{l}\text { a) } 24 \\
\text { b) } 24\end{array}$ & $\begin{array}{l}\text { a) } 24 \\
\text { b) } 24\end{array}$ & $\begin{array}{l}\text { a) } 24 \\
\text { b) } 24\end{array}$ & $\begin{array}{l}\text { a) } 24 \\
\text { b) } 24\end{array}$ & $\begin{array}{l}\text { a) } 24 \\
\text { b) } 48\end{array}$ & \\
\hline Load locations (L) & $\begin{array}{l}\text { a) } 1 / 2 \\
\text { b) } 1 / 3,1 / 2,2 / 3\end{array}$ & $\begin{array}{l}\text { a) } 1 / 2 \\
\text { b) } 1 / 3,1 / 2,2 / 3\end{array}$ & $\begin{array}{l}\text { a) } 1 / 2 \\
\text { b) } 1 / 3,1 / 2,2 / 3\end{array}$ & $\begin{array}{l}\text { a) } 1 / 2 \\
\text { b) } 1 / 2\end{array}$ & $\begin{array}{l}\text { a) } 1 / 2 \\
\text { b) } 1 / 2\end{array}$ & \\
\hline Static parameters & $\begin{array}{l}\text { a) } D \\
\text { b) } D\end{array}$ & $\begin{array}{l}\text { a) } D \\
\text { b) } D\end{array}$ & $\begin{array}{l}\text { a) D } \\
\text { b.1) D } \\
\text { b.2) } S\end{array}$ & $\begin{array}{l}\text { a) } D \\
\text { b) D }\end{array}$ & $\begin{array}{l}\text { a.1) D } \\
\text { a.2) } \mathrm{S} \\
\text { b) } \mathrm{S}\end{array}$ & \\
\hline Noise (\%) & $\begin{array}{l}\text { a) } 0,1,5,10 \\
\text { b) } 5\end{array}$ & $\begin{array}{l}\text { a) } 0,1,5,10 \\
\text { b) } 5\end{array}$ & $\begin{array}{l}\text { a) } 0,1,5,10 \\
\text { b.1) } 5 \\
\text { b.2) } 5\end{array}$ & $\begin{array}{l}\text { a) } 0,1,5,10 \\
\text { b) } 0,1,5,10\end{array}$ & $\begin{array}{l}\text { a.1) } 5 \\
\text { a.2) } 5 \\
\text { b) } 5 \\
\end{array}$ & \\
\hline $\begin{array}{l}\text { Measurements } \\
\text { number }\end{array}$ & $\begin{array}{l}\text { a) } 24 \\
\text { b) } 24\end{array}$ & $\begin{array}{l}\text { a) } 24 \\
\text { b) } 24\end{array}$ & $\begin{array}{l}\text { a) } 24 \\
\text { b.1) } 24\end{array}$ & $\begin{array}{l}\text { a) } 24 \\
\text { b) } 24\end{array}$ & $\begin{array}{l}\text { a.1.1) } 12 \\
\text { a.1.2) } 24\end{array}$ & $\begin{array}{l}\text { a.2.3) } 48 \\
\text { b.1) } 12\end{array}$ \\
\hline
\end{tabular}




\begin{tabular}{|c|c|c|c|c|c|c|}
\hline & & & \multicolumn{2}{|l|}{ b.2) 24} & \multirow{3}{*}{$\begin{array}{l}\text { a.1.3) } 48 \\
\text { a.2.1) } 12 \\
\text { a.2.2) } 24\end{array}$} & \multirow{3}{*}{$\begin{array}{l}\text { b.2) } 24 \\
\text { b.3) } 48\end{array}$} \\
\hline & & & & & & \\
\hline & & & & & & \\
\hline \multirow[t]{5}{*}{ Damage types } & a) Single & a) Single & a) Single & a) Sporadic & a.1.1) Sp & a.2.3) Sp \\
\hline & b) Single & b) Single & b.1) Single & b) Neighbour & a.1.2) Sp & b.1) Sp \\
\hline & & & b.2) Single & & a.1.3) Sp & b.2) Sp \\
\hline & & & & & a.2.1) Sp & b.3) Sp \\
\hline & & & & & a.2.2) Sp & \\
\hline
\end{tabular}

\subsubsection{Single damage}

\subsubsection{Case 1: Damaged concrete slab}

In this case, a steel-concrete composite beam without bonding slip is considered. It is assumed that damage occurs at a $10 \%$ reduction of elemental stiffness in Element 21 where $\boldsymbol{\alpha}_{c}=\{0,0, \ldots, 0,0,0.1,0,0,0\}^{T}$. The displacement values obtained from 24 measurements located equally along the beam have been polluted by noises of 1,5 and 10 percent. This analysis is repeated for the static loads at $L / 3, L / 2$ and $2 L / 3$. Since the identification of true damage index is not possible, the results are compared with the identified results with no measurement noise.
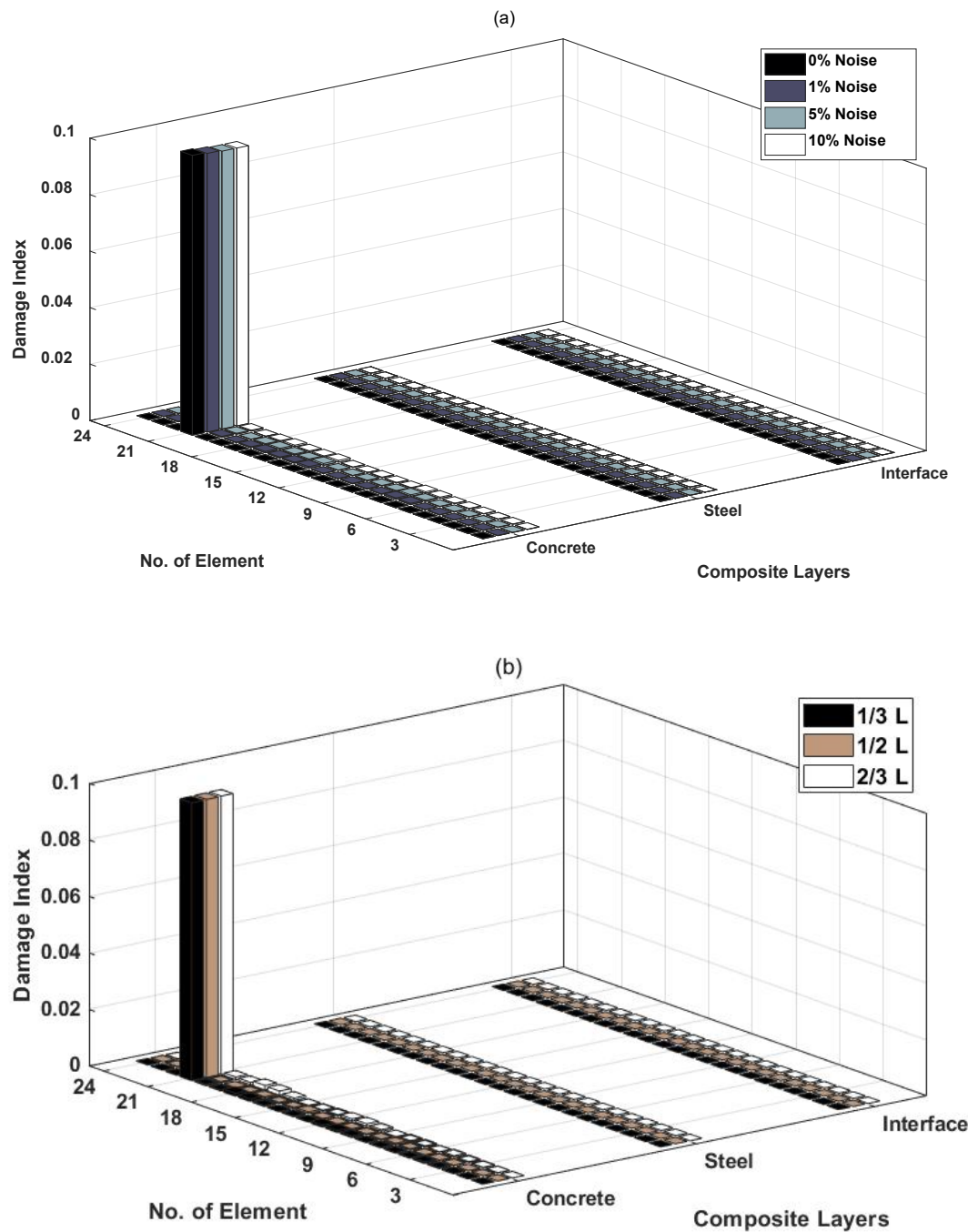

Figure 8. The damage indices identified for the concrete slab from the displacement measurements in terms of (a) the noise level and (b) different load locations 
Figure 8 shows the damage indices identified for the concrete slab where a single damage has been introduced close to the left hand side support. This analysis is first carried out in terms of different noise levels when a load is applied at the middle of the span; the results are then compared to the approximate true value (Figure 8.a). Here, the damage indices are very close to those without noise, which indicates they are insensitive to the contaminated measurements. Second, the effect of static load locations are considered in the analyses with $5 \%$ of white noise (Figure $8 . b$ ). It is shown that the load location has no significant effect on the damage identification. The results presented in Figure 8 confirm effectiveness of the proposed method in determining the damage location.

\subsubsection{Case 2: Damaged steel girder}

In this case, a perfect connection between a steel girder and a concrete slab is considered. It is assumed that $10 \%$ damage occurs at Element 21 where $\boldsymbol{\alpha}_{s}=\{0,0, \ldots, 0,0,0.1,0,0,0\}^{T}$. The displacements obtained from 24 measurements located equally along the beam have been affected by 1,5 and 10 percent noises. This analysis is established in terms of the noise level and the static load locations.
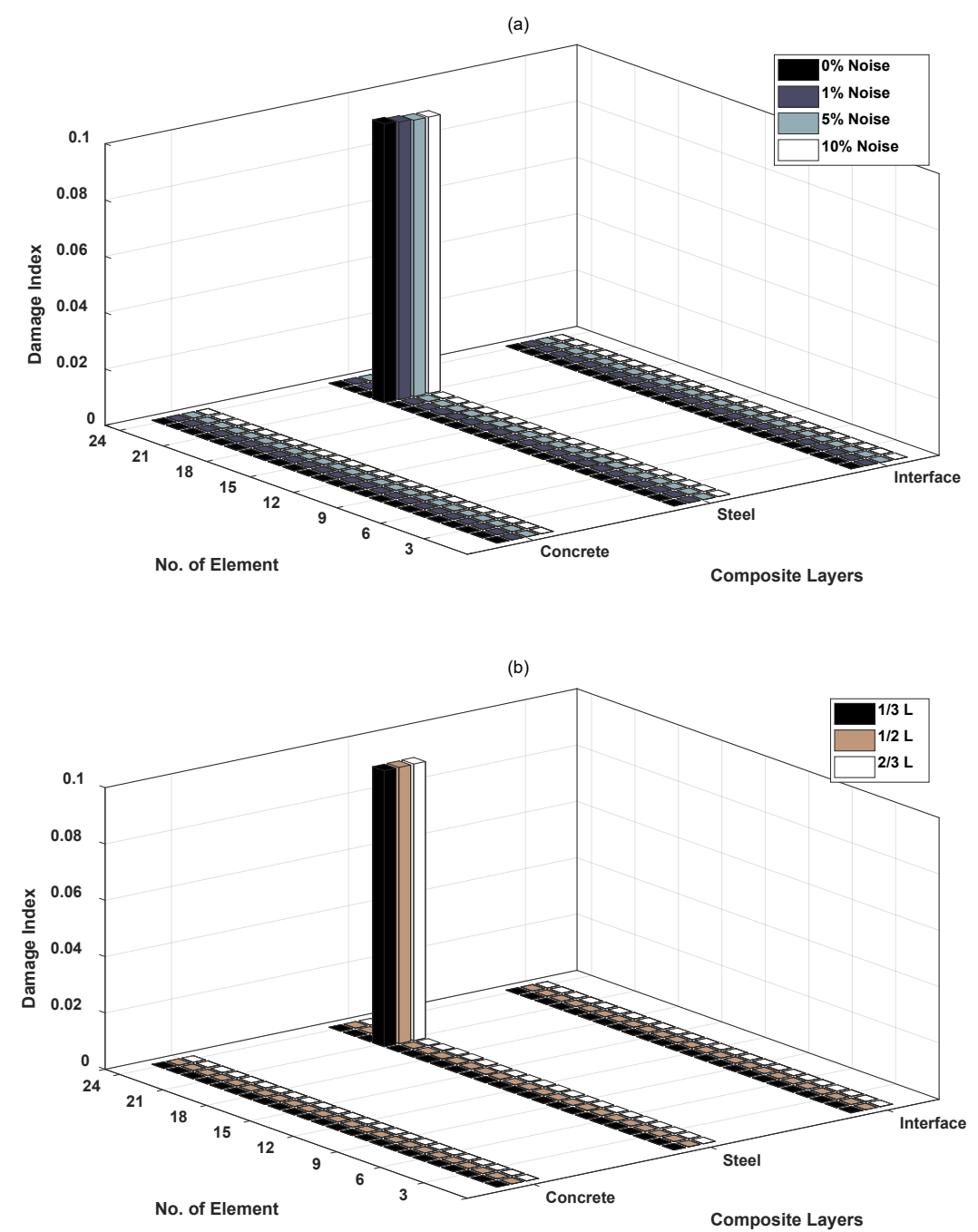

Figure 9. The damage indices identified for the steel girder from the displacement measurements in terms of (a) the noise level and (b) different load locations

Figure 9 shows the damage indices identified for the steel girder where a single damage exists close to the left hand side support. This analysis has been established in terms of different noise levels when a load is applied at the middle of the span, and the results are compared with the approximate true value (Figure 9.a); 
here, the identified damage indices are very close to true values, which indicate they are insensitive to the noisy measurements. Moreover, the effect of static load locations are considered in the analyses with $5 \%$ of white noise (Figure 9.b); here, the damage indices are almost the same that demonstrates the load location does not affect the damage indices.

\subsubsection{Case 3: Bonding loss}

A steel-concrete composite beam with a bonding loss is considered in this case. It is assumed that $15 \%$ of bonding damage has occurred at Element 21 where $\boldsymbol{\alpha}_{b}=\{0,0, \ldots, 0,0,0.15,0,0,0\}^{T}$. The displacements obtained from 24 measurements located equally along the beam have been contaminated with noise at 1, 5 and 10 percent. This analysis is repeated for the loading at $L / 3, L / 2$ and $2 L / 3$.
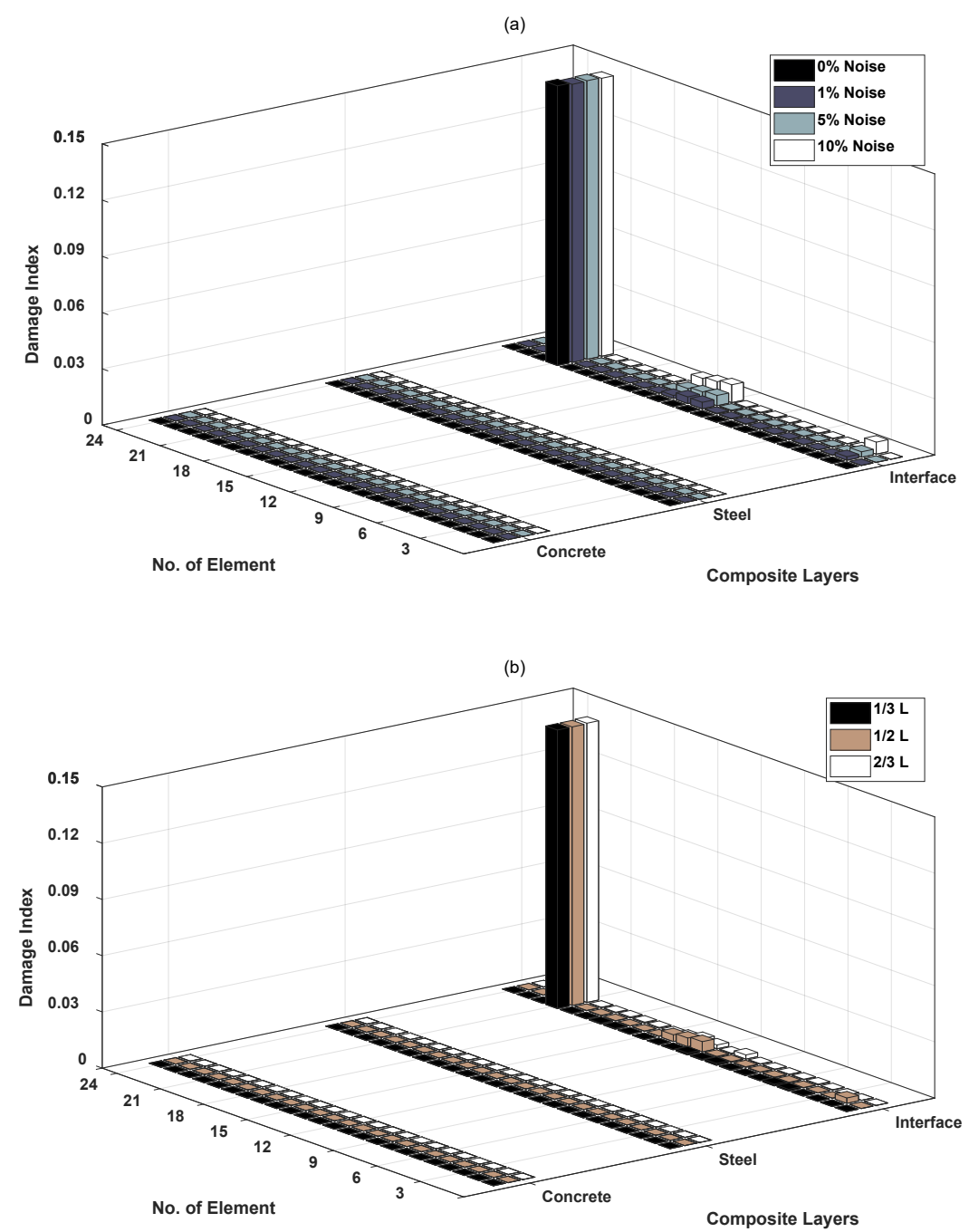

Figure 10. The damage indices identified for the bonding from the displacement measurements in terms of (a) the noise level and (b) different load locations

Figure 10 shows the damage indices identified for the interface when a single damage is assumed. In Figure 10.a, the analysis has been established in terms of different noise levels when a load is applied at the middle of the span; the results are then compared with the approximate true value. Although the damage in interface has been identified with a reasonable error, this small severity has no effect on the upper and lower layers. This is realistic because it is demonstrated in reference [12] that the contribution made by the bonding stiffness in the composite beam stiffness is very small and consequently any damage that defined by reduction in the interface stiffness has less effect on the composite layers stiffness. Since there are some 
incoherencies in the damage indices when the noise levels are changed, this procedure is iterated using strain values. Figure 11 shows that the damage indices identified from the strain measurements give a better result than the previous case. Here the identified damage indices are almost accurate, which shows they are insensitive to the polluted measurements. The effect of static load locations are also considered in the analyses in the presence of $5 \%$ white noise (Figure 10.b). It is shown that the load location changes do not have remarkable effect on the bonding damage indices. In Figures 8.b, 9.b and 10.b, although the location of the load has no significant effect on the damage indices, vicinity of the load location to the damage and support may well help to identifying the damage. Furthermore, the results shown in Figures 8-11 confirm that the proposed method can determine effectively the location of damage may occur individually in each layers of the composite beam.

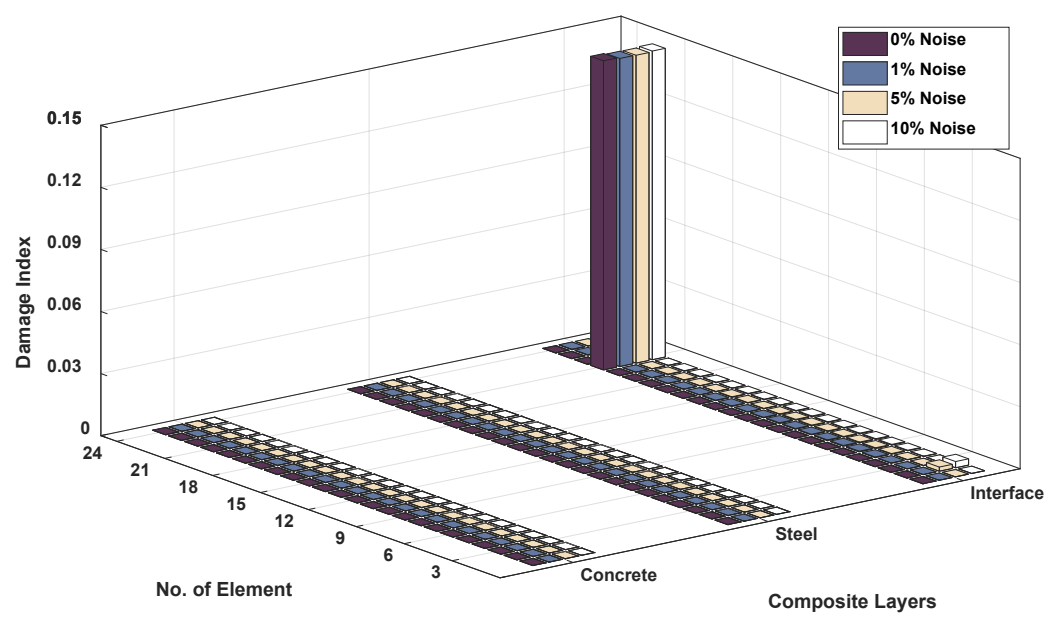

Figure 11. The damage indices identified for the bonding from the strain measurements in terms of noise levels

\subsubsection{Double damage}

\subsubsection{Case 4: Damaged concrete slab and steel girder}

The steel-concrete composite beam without bonding slip is considered in this case. The effects of multiple damage in sporadic and neighbour elements are investigated separately. The sporadic damage (Figure 7, Case 4.a) occurs at Element 21 in the concrete slab, $\boldsymbol{\alpha}_{c}=\{0,0, \ldots, 0,0,0.1,0,0,0\}^{T}$ and Element 4 in the steel girder, $\boldsymbol{\alpha}_{s}=\{0,0,0,0.1, \ldots, 0,0\}^{T}$.

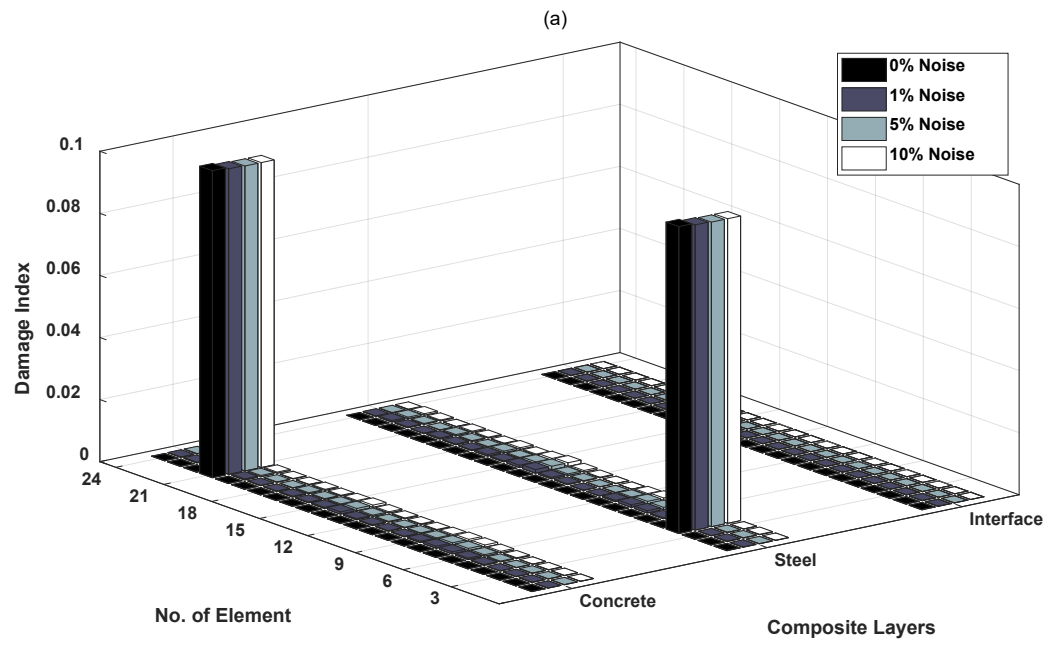




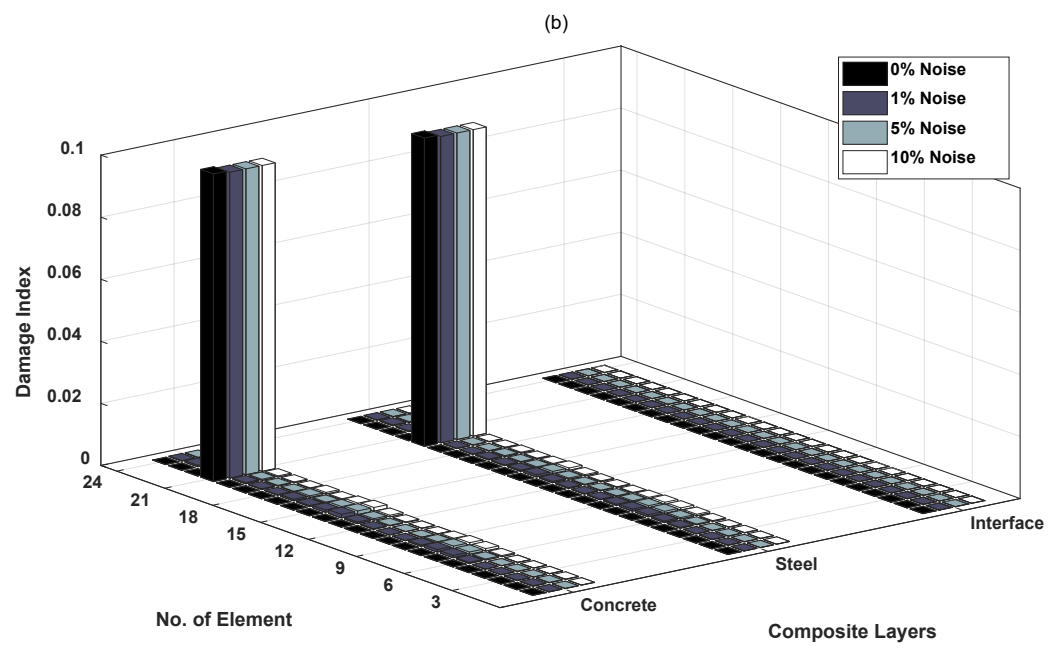

Figure 12. The damage indices identified for the concrete slab and steel girder from the displacement measurements in terms of (a) two distributed elements and (b) two grouped elements

Two neighbour Elements (Figure 7, Case 4.b), 20 for the steel girder and 21 for the concrete slab, $\boldsymbol{\alpha}_{c, s}=$ $\{0,0, \ldots, 0,0.1,0.1,0,0,0\}^{T}$ are then subjected to damage. The composite beam is under the same static load at the middle of the span. Three levels of noise $1 \%, 5 \%$ and $10 \%$ are added to the displacement responses measured by 24 measurements located evenly along the beam. Figure 12 shows the damage indices identified for the concrete slab and steel girder. These analyses are in terms of different noise levels; the results confirm that the proposed method can detect multiple damage that may occur in different spots or a zone.

\subsubsection{Triple damage}

\subsubsection{Case 5: Damage on concrete, steel and bonding}

\section{a) Effects of static parameters and the number of measurements}

The effects of concurrent multiple damages on the concrete slab, steel girder and bonding interface are considered in this section, albeit identification in this case (Figure 7, Case 5.a) is complicated due to interaction between the multiple type damage. However, this is used to examine how well the proposed method can detect each layer independently. It is assumed here that bonding damage occurs at Element 4, $\boldsymbol{\alpha}_{b}=\{0,0,0,0.15, \ldots, 0\}^{T}$, and damage of the concrete slab and steel girder are in Elements 21 and 17, respectively, $\boldsymbol{\alpha}_{c, s}=\{0,0,0,0.1, \ldots, 0.1, \ldots, 0\}^{T}$.

Figure 13 shows the damage indices identified from the displacement values obtained separately from 12 , 24 and 48 measurements, and with 5\% noise. The damage indices for the concrete slab and steel girder are very close to the introduced (true) value, but there are unexpected increments when the number of measurements changes, and moreover, there are some inconsistencies in the other elements possibly due to the effect of bonding damage. A smeared spot has been identified for bonding damage. Since the contribution made by the bonding stiffness in the composite beam stiffness is very small, the severity of the damage from the concrete slab and steel girder are greater than the bonding damage. Therefore, identifying the bonding damage is more complicated, and must be considered more precisely. 


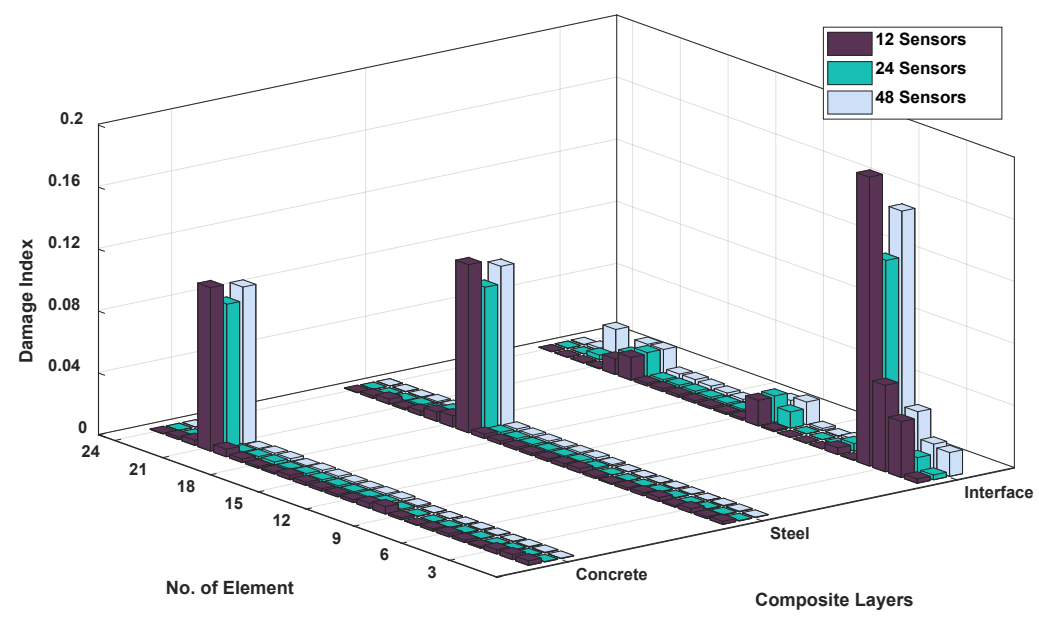

Figure 13. The damage indices identified for the concrete slab, steel girder and bonding from the displacement measurements in terms of different number of measurements

Case 3 shows that the damage indices from the strain values are more explicit and less sensitive to noise (Figure 11) compared to that of the displacements (Figure 10.a), so the identification process is repeated using strain values to reach more reliable values. Figure 14 shows the identified damage indices from the strain values as obtained separately from 12,24 and 48 measurements. Like the previous case, $5 \%$ noise is also added to the strain values. The smeared zones have almost eased off, thus confirming the effectiveness of stain parameter in the damage identification when the beam is slightly deformed. Another important contribution to this analysis is the number of measurements. The results confirm that the increment of the measurements does not necessarily improve the identified damage indices, but it does lead to interaction between the responses measured in a noisy environment. Therefore, to obtain a reliable damage identification, it is important to select an optimal number of measurements.

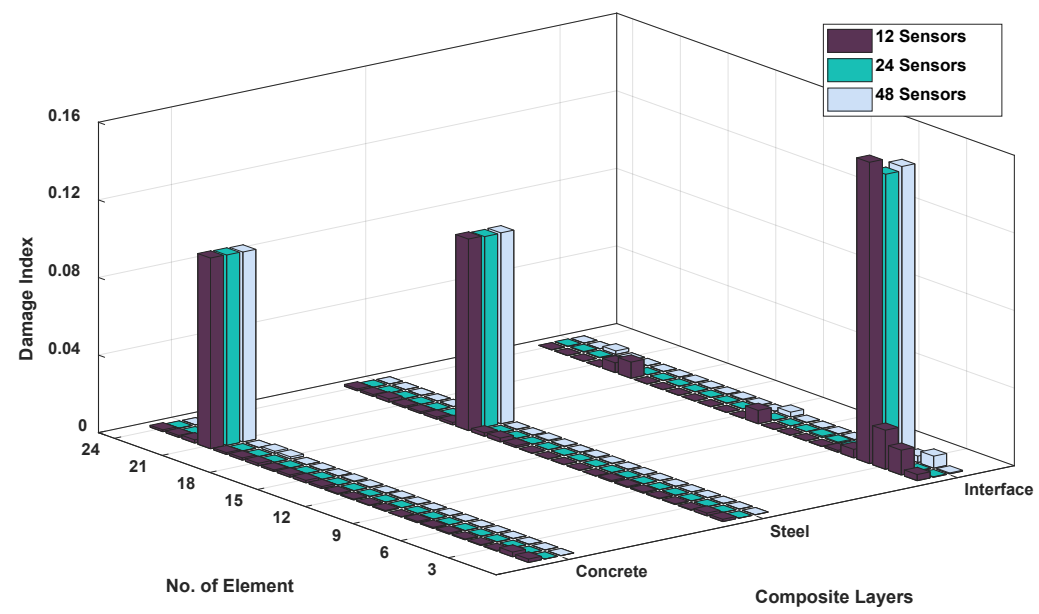

Figure 14. The damage indices identified for the concrete slab, steel girder and bonding from the strain measurements in terms of different number of measurements

\section{b) Effects of mesh sizes}

In order to study the effect of the FE mesh size on the identified damage indices, each FE is refined by dividing it into two elements, so the overall number of FEs becomes 48 with similar damage parameters for the concrete slab, steel girder and bonding interface. This means the layout of the damaged elements remains 
constant but their quantities are doubled. Therefore, the introduced damage vector has values for the concrete slab in Elements 41 and 42, for the steel girder in Elements 33 and 34, and for the bonding in Elements 7 and 8 (Figure 7, Case 5.b). The strain responses measured from 12, 24 and 48 measurements are used for the damage identification with $5 \%$ added noise. The concurrent multiple damage is also considered in this case and the identified results are presented independently. Figure 15 shows the identified damage indices for the composite beam with $48 \mathrm{FEs}$ that are presented in terms of different numbers of measurements.

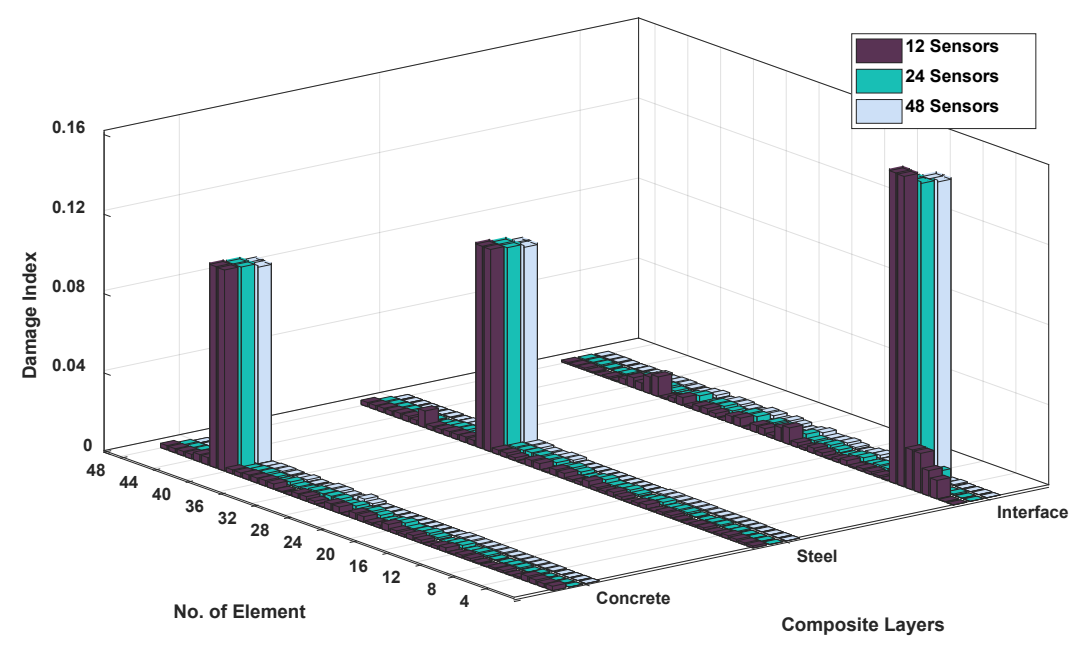

Figure 15. The damage indices identified for the concrete slab, steel girder and bonding from the strain measurements in terms of different numbers of measurements

The results show that the identified damage indices have almost the same values as those presented in Figure 13 , while the number of FEs and measurements are changed regularly. When 12 measurements are used for $24 \mathrm{FEs}$, the error in the identification is less than those with $48 \mathrm{FEs}$. The accuracy of the results identified in the case with 48 measurements (Figure 15), is better than the others. The small variations in the results identified on the other elements through the beam could be due to the effect of the bonding loss. The results from Figures 14 and 15 confirm that the increments of FEs and measurements do not necessarily enhance the accuracy of the damage identification. An acceptable relationship between the numbers of FEs and measurements must be taken considered in order to give the best results, particularly when the bonding loss is the main issue.

\section{Suggestion for practical application}

The steel-concrete composite bridge deck is widely used in bridge constructions in Australia. This is due to the unique characteristics of steel-concrete composite elements such as being lightweight with high stiffness and strength. When an external loading outreaches the bonding of a steel-concrete composite member (as a component of a structural system), it results a relative displacement between its layers that can affect the whole system. The damage identification of complex structures such as bridges are faced with difficulties due the large quantity of analytical model that leads to inaccuracy in the assessment. To address this issue, one way is to consider a smaller part of the structure as a substructure in the analysis. This is useful because the number of unknown parameters is also reduced. Therefore, the steel-concrete composite members are considered individually as the substructures of a system and the proposed method can be applied for identifying their possible damage.

\section{Conclusion}


In this paper, a steel-concrete composite element with a bonding interface has been developed based on the displacement-based FE formulation, and a damage identification method based on this composite element has been proposed. The static responses are acquired at undamaged and different cases of damaged states by adding the white noise. The proposed algorithm is applied for the damage identification of the composite beam form the static responses obtained from the analytical FE model. The findings from this numerical analysis are as follows:

- This method is effective and accurate to detect small damage in the concrete slab, steel girder and bonding interface of the composite beam, even with $10 \%$ of measurement noise.

- This method is robust to the measurement noise, and the location of loading has no significant effect on the identified results.

- The effect that the number of measurements has on both displacement and strain responses has also been investigated. It has been shown that the identification is more accurate when the number of measurements are adequate than the number of FEs.

- The identification from strain responses is more accurate than with displacement measurements because they are not as sensitive to the measurement noise.

- The effect of FE mesh sizes has been investigated, and it is shown that the increment of FEs does not give a good result unless the number of measurements is also increased.

\section{References}

[1] Doebling SW, Farrar CR, Prime MB, Shevitz DW. Damage identification and health monitoring of structural and mechanical systems from changes in their vibration characteristics: A literature review. Damage Identification and Health Monitoring of Structural and Mechanical Systems from Changes in Their Vibration Characteristics: A Literature Review. 1996.

[2] Farrar CR, Doebling SW, Nix DA. Vibration-based structural damage identification. Philosophical Transactions of the Royal Society of London A: Mathematical, Physical and Engineering Sciences. 2001;359:131-49.

[3] Doebling SW, Farrar CR, Prime MB. A summary review of vibration-based damage identification methods. Shock and vibration digest. 1998;30:91-105.

[4] Fan W, Qiao P. Vibration-based damage identification methods: a review and comparative study. Structural Health Monitoring. 2011;10:83-111.

[5] Shen H-S. A novel technique for nonlinear analysis of beams on two-parameter elastic foundations. International Journal of Structural Stability and Dynamics. 2011;11:999-1014.

[6] Sohn H, Farrar CR, Hemez FM, Shunk DD, Stinemates DW, Nadler BR et al. A review of structural health monitoring literature: 1996-2001. Los Alamos National Laboratory, USA. 2003.

[7] Yang Y, Yang JP. State-of-the-art review on modal identification and damage detection of bridges by moving test vehicles. International Journal of Structural Stability and Dynamics. 2018;18:1850025.

[8] Choi I-Y, Lee JS, Choi E, Cho H-N. Development of elastic damage load theorem for damage detection in a statically determinate beam. Computers \& Structures. 2004;82:2483-92.

[9] Zhang X, Zhu S, Xu Y, Homg X. Integrated optimal placement of displacement transducers and strain gauges for better estimation of structural response. International journal of structural stability and dynamics. 2011;11:581-602.

[10] Feng D, Feng MQ. Computer vision for SHM of civil infrastructure: From dynamic response measurement to damage detection-A review. Engineering Structures. 2018;156:105-17.

[11] Luo L, Feng MQ, Wu ZY. Robust vision sensor for multi-point displacement monitoring of bridges in the field. Engineering Structures. 2018;163:255-66.

[12] Zhu XQ, Law SS. A concrete-steel interface element for damage detection of reinforced concrete structures. Engineering Structures. 2007;29:3515-24.

[13] Raghuprasad B, Lakshmanan N, Gopalakrishnan N, Sathishkumar K, Sreekala R. Damage identification of beam-like structures with contiguous and distributed damage. Structural Control and Health Monitoring. 2013;20:496-519. 
[14] Li J, Hao H, Fan K, Brownjohn J. Development and application of a relative displacement sensor for structural health monitoring of composite bridges. Structural Control and Health Monitoring. 2015;22:72642.

[15] Caddemi S, Caliò I, Cannizzaro F, Morassi A. A procedure for the identification of multiple cracks on beams and frames by static measurements. Structural Control and Health Monitoring. 2018:e2194.

[16] Le NT, Thambiratnam D, Nguyen A, Chan TH. A new method for locating and quantifying damage in beams from static deflection changes. Engineering Structures. 2019;180:779-92.

[17] Huang C, Su Y. Dynamic characteristics of partial composite beams. International Journal of Structural Stability and Dynamics. 2008;8:665-85.

[18] Wang J, Ren J, Zhang Y. Vibration Analysis of Carbon Fiber-Reinforced Steel-Concrete Composite Beams Considering Shear-Slip Effects. International Journal of Structural Stability and Dynamics. 2019:1950077.

[19] Ayoub A, Filippou FC. Mixed formulation of nonlinear steel-concrete composite beam element. Journal of Structural Engineering. 2000;126:371-81.

[20] Chen J, Zhang H, Yu Q-Q. Static and fatigue behavior of steel-concrete composite beams with corroded studs. Journal of Constructional Steel Research. 2019;156:18-27.

[21] Nguyen Q-H, Hjiaj M, Guezouli S. Exact finite element model for shear-deformable two-layer beams with discrete shear connection. Finite Elements in Analysis and Design. 2011;47:718-27.

[22] Nguyen Q-H, Martinelli E, Hjiaj M. Derivation of the exact stiffness matrix for a two-layer Timoshenko beam element with partial interaction. Engineering Structures. 2011;33:298-307.

[23] Ferrer M, Marimon F, Casafont M. An experimental investigation of a new perfect bond technology for composite slabs. Construction and Building Materials. 2018;166:618-33.

[24] Pathirana SW, Uy B, Mirza O, Zhu X. Flexural behaviour of composite steel-concrete beams utilising blind bolt shear connectors. Engineering Structures. 2016;114:181-94.

[25] Ni Y-Q, Xia Y-X. Strain-based condition assessment of a suspension bridge instrumented with structural health monitoring system. International Journal of Structural Stability and Dynamics. 2016;16:1640027.

[26] ABAQUS. Online documentation help, theory manual: Dassault Systems. V. 6.14 edAccessed on; 2016.

[27] Adekola A. Partial interaction between elastically connected elements of a composite beam. International Journal of Solids and Structures. 1968;4:1125-35.

[28] Amadio C, Fragiacomo M. A finite element model for the study of creep and shrinkage effects in composite beams with deformable shear connections. Costruzioni Metalliche. 1993;4:213-28.

[29] Hjelmstad K, Banan MR, Banan MR. Time-domain parameter estimation algorithm for structures. I: Computational aspects. Journal of engineering mechanics. 1995;121:424-34.

[30] Banan MR, Hjelmstad KD. Identification of structural systems from measured response. Technical Report from University of Illinois Engineering Experiment Station; 1993.

[31] Banan MR, Banan MR, Hjelmstad K. Parameter estimation of structures from static response. II: Numerical simulation studies. Journal of structural engineering. 1994;120:3259-83.

[32] Kelley CT. Iterative methods for optimization: SIAM; 1999.

[33] Uy B, Hicks S. AUSTRALIA/NEW ZEALAND STANDARD FOR COMPOSITE STRUCTURES, AS/NZS 2327.

[34] .1 AN. Structural Design Actions, Part 1: Permanent, Imposed and Other Actions. Standards Australia Sydney; 2002.

[35] Dávila CG, Camanho PMPRd, Turon Travesa A. Cohesive elements for shells. (C) NASA TP Technical Reports, 2007, núm 214869. 2007.

[36] Simulia DS. ABAQUS 6.13 User's manual. Dassault Systems, Providence, RI. 2013. 